\title{
An approach to gut microbiota profile in children with autism spectrum
}

\section{disorder}

\section{Authors}

Pedro Andreo-Martínez a,b*, Nuria García-Martínez a,, Elvira Pilar Sánchez-Samper c,d, Agustín Ernesto Martínez-González e*,

${ }^{\text {a }}$ Department of Agricultural Chemistry, Faculty of Chemistry. University of Murcia. Campus of Espinardo. 30100 Murcia, Spain.

${ }^{\mathrm{b}}$ Department of Chemical Engineering, Faculty of Chemistry. University of Murcia, Campus of Espinardo, 30071 Murcia, Spain.

${ }^{\mathrm{c}}$ Research group of Human Nutrition \& Food Sciences (NUTBRO), Veterinary Faculty, Regional Campus of International Excellence “Campus Mare Nostrum”, University of Murcia, Spain.

${ }^{\mathrm{d}}$ Murcian Institute of Biosanitary Research Virgen de la Arrixaca (IMIB), AREA 3,

Digestive and Endocrine-Metabolic Diseases, Nutrition research line, Murcia, Spain.

e Department of Developmental Psychology and Didactics, University of Alicante, Alicante, Spain.

*Corresponding author: Agustín Ernesto Martínez-González. E-mail: agustin.emartinez@ua.es differences between this version and the Version of Record. Please cite this article as doi: $10.1111 / 1758-2229.12810$ 


\begin{abstract}
In recent years, there has been an increase in studies on the implications of gut microbiota (GM) on the behavior of children with autism spectrum disorders (ASD) due to a dysbiosis in GM that can trigger onset, development or progression of ASD through the microbiota-gutbrain axis. The aim of this study is to carry out a systematic review of articles from the last 6 years that analyze GM in children with ASD compared to GM in control groups. Children with ASD showed higher abundance of Roseburia and Candida genera, and lower abundance of Dialister, Bilophila, Veillonella, Streptococcus, Coprococcus and Prevotella genera. Those differences can be attributed to factors such as different nationalities, nature of control groups, place where the sample was taken, gastro-intestinal (GI) problems or bacterial detection methods. It is still too early to define a specific GM profile of children with ASD, and future studies should focus on homogenizing the characteristics of samples and control groups. Further, new multicenter studies should also focus on the impact of GM on: GI physiology, neurophysiology and behavior of children with ASD, and on performing psychometric analyses of the correlation between the severity of ASD behavioral symptoms and GM profiles.
\end{abstract}

Keywords: Gut Microbiota; Children; Autism Spectrum Disorders (ASD); Dysbiosis; Microbiota-gut-brain axis; Systematic review 


\section{Introduction}

Gut microbiota (GM) represents about 99\% of the entire human microbiome (Frye et al., 2017). It weighs approximately $1 \mathrm{~kg}$ (containing about 9.9 million bacterial genes) (Li et al., 2017), and it is composed of: $92.9 \%$ bacteria, $0.5 \%$ eukaryotes, $0.8 \%$ archaeas and $5.8 \%$ viruses (Arumugam et al., 2011). Gut microbiota abundance ranges from about $10^{8}$ bacteria/g measured in ileum to $10^{11}$ bacteria/g measured in stool (Sender et al., 2016), with Bacteroidetes, Firmicutes, Proteobacteria, Actinobacteria, and Fusobacteria being the major bacterial phyla in the mammalian gastro-intestinal (GI) tract (Hill et al., 2010). Recently, the development of human GM at the phylogenetic level has been related to the type of food intake and the preparation methods (e.g. food cooked on fire or boiled) (Danchin, 2018). However, there are cultural and geographical differences in GM composition. Prevotella, Proteobacteria, Spirochaetes, Clostridiales and Ruminobacter, were highly abundant in the gut microbiota of the hunter-gatherer populations, while those of urban communities are often enriched in Bacteroides, Bifidobacterium, and Firmicutes. There are also variations in the composition of GM between different nationalities and latitudes (Lindström and Langenheder, 2012; Suzuki and Worobey, 2014; Gupta et al., 2017; Cerdo et al., 2018). 
GM may play an important role in the production of several metabolites such as propionic acid (PPA), other short chain fatty acids (SCFAs), and gaseous molecules, which can induce effects on the GI tract, brain and behavior (MacFabe, 2015). These metabolites can produce effects via biochemical, immunological, and neuroendocrine mechanisms that involve endogenous and microbial modulators and transmitters (Frye et al., 2017). Changes in redox signaling, epigenetic transcriptional factors, lipid and mitochondrial metabolism, ion channel/gap junction/transporter regulation protein, and post-translational modification have also been reported (Frye et al., 2016; Rose et al., 2017). In addition, other biomarkers such as serotonin, p-cresol and cortisol have also been related to etiology and behavior in mental disorders such as Autism Spectrum Disorder (ASD) (Yang et al., 2015; Ferguson et al., 2016; Ooi et al., 2017; Kang et al., 2018).

Recent studies have indicated that it is necessary to continue investigating the interaction between GM and the epithelial cells of the GI tract because GM seems to act as an epigenetic regulator of several diseases (Kumar et al., 2014). Thus, dysbiosis or imbalances in the GM can induce intestinal inflammation that is associated with the pathogenesis of several diseases such as obesity, Crohn's disease, irritable bowel syndrome, ObsessiveCompulsive Disorder, Depression, Anxiety, type 2 diabetes mellitus and neurodegenerative diseases including Alzheimer’s and ASD (Durbán et al., 2012; Mangiola et al., 2016; Schäffler et al., 2016; Ding et al., 2017; Pradhan et al., 2017; Sanchez-Samper et al., 2017). GM maturation occurs during the first years of life, coinciding with the critical window of early brain development and, at the third year of life, the GM of children is similar to that of adults (Diaz Heijtz, 2016). It is also known that the microbiota may continue to 
develop into adolescence (Hollister et al., 2015). In this sense, the first years of life are an important period for the appearance of neurodevelopmental disorders (Borre et al., 2014). At present, the microbiota-gut-brain axis is an explanatory model that attempts to relate, among others, ASD symptoms with findings in neuroscience and bacteriology. The microbiota-gutbrain axis is defined as a bi-directional communication system between the neuronal, immune, endocrine and metabolic pathways, but it still requires better understanding (Sudo et al., 2004; Hiippala et al., 2016; Kantarcioglu et al., 2016).

In recent years, there has been an increase in studies indicating a higher prevalence of GI problems in children with ASD compared to healthy children. Specifically, children with ASD have higher rates of diarrhea, constipation and abdominal pain (McElhanon et al., 2014; Krajmalnik-Brown et al., 2015; Martínez-González and Andreo-Martínez, 2019). Thus, children with ASD and with GI problems exhibit more irritability and agitated behavior than children with ASD who do not have GI problems (Rose et al., 2018). On the other hand, some studies indicate that children with ASD present feeding problems. Specifically, they have a greater sensitivity to certain foods or food allergies (Xu et al., 2018) and they have a significantly lower intake of calcium and protein (McElhanon et al., 2014). However, the etiology of the nutritional and GI problems of ASD remains unknown (McElhanon et al., 2014; Ferguson et al., 2016; Martínez-González and Andreo-Martínez, 2019) and everything seems to indicate that it is a combination of associated factors (Buie, 2015). Other authors suggest that abnormal GM in ASD may be caused by the overuse of antibiotics (Sandler et al., 2000; Krajmalnik-Brown et al., 2015; Wimberley et al., 2018) or a pathophysiological cascade of interactions between environmental factors and key genes. In addition, the 
neurological alterations associated with atypical growth of the head in children with ASD during the uterine period, which occurs more frequently in late gestations, can also be a possible trigger of ASD (Bonnet-Brilhault et al., 2018).

A recent review up to 2013 reported the different gut microbes involved in ASD (Ding et al., 2017). It seems that higher abundance of Clostridium (Clostridium clostridioforme or Clostridium bolteae) and Sutterella genera have been found in children with ASD and with GI problems, while lower levels of Prevotella genus have been found in children with ASD. A more recent systematic review up to 2018 reported elevated abundance of Proteobacteria, Lactobacillus, Bacteroides, Desulfovibrio, and Clostridium, and decreased abundance of Bifidobacterium, Blautia, Dialister, Prevotella, Veillonella, and Turicibacter in children with ASD compared to healthy controls (Liu et al., 2019). There are also other studies and previous reviews in scientific literature about GM and ASD (Wang et al., 2011; Cao et al., 2013; De Angelis et al., 2015; Krajmalnik-Brown et al., 2015; Andreo-Martínez et al., 2019; Martínez-González and Andreo-Martínez, 2019). Although there have been advances in the study of GM in ASD (Ding et al., 2017; Liu et al., 2019), the latest review studies have not been conducted following the Preferred Reporting Items for Systematic Reviews and Meta-Analyses (PRISMA) guidelines (Moher et al., 2015) within the past six years. Consequently, this study aims to conduct an updated systematic review of the findings of the most common bacterial populations and their abundance in the GM of children with ASD compared to control groups. We expect to find some bacterial population patterns in children with ASD compared to children who do not have this disorder. 
The method followed to carry out the present systematic review is described in detail in supporting information, and Figure 1 shows the process of identifying articles for inclusion.

\section{Figure 1}

\section{Dysbiosis of the GM in ASD}

Table 1 shows the twenty-one articles included in the present systematic review and the results of the analysis of the samples of children with ASD. The gut microbes that showed significantly different abundance in ASD at phylum, family, genus, and specie levels, according to the articles found in the present review, are listed in Figure 2. The phylogenetic tree of this figure was drawn with the help of the Interactive Tree Of Life (iTOL) web-based tool (Letunic and Bork, 2016).

\section{Figure 2}

Gut microbiota dysbiosis found in ASD

Nineteen articles found significant differences in some gut microbes’ abundance in children with ASD (Table 1) compared to their respective control groups. Specifically, there are 6 bacteria phyla, 16 bacterial families, 1 presumptive bacterial family, 48 bacterial genera, 4 presumptive bacterial genera groups, 1 presumptive bacterial genus and 19 bacterial species of Bacteria domain, and one genus of the Fungi kingdom. 
Two studies found no differences in the GM composition of children with ASD (Gondalia et al., 2012; Son et al., 2015). Therefore, the present review expands upon the number of bacteria previously reported (Cao et al., 2013; Ding et al., 2017; Liu et al., 2019). Of note, the recent systematic review published by Liu et al. (2019) reported on different articles from those included in the present systematic review, as they used different inclusion/exclusion criteria such as the inclusion of articles that only analyzed GM by culture-independent methods or the time-frame chosen (from inception to March 2018).In addition, some works have shown contradictory results regarding the nature and/or extent of GM abundance in children with ASD as discussed by Krajmalnik-Brown et al. (2015) and Liu et al. (2019).

The gut microbe abundance of two bacterial phyla, 4 bacterial families, 19 bacterial genera, one genus of the Fungi kingdom and two bacterial species, were found to be significantly different in children with ASD compared to their control groups by more than one article. Among those gut microbes, the abundance of 7 bacterial genera and Candida were reported to be similar, while the rest showed abundance discrepancies (Table 1).

The highest number of GM components studied by more than one article was found in Firmicutes phylum (12), followed by Actinobacteria phylum (5), Bacteroidetes phylum (4) and, Proteobacteria phylum (2) and the Deuteromycota phylum (1).

\section{High abundance of some gut microbes in ASD}

One bacterial phylum, eight bacterial families, one presumptive bacterial family, thirteen bacterial genera, two presumptive bacterial genera groups, one fungi genus, and 
twelve bacterial species were found to have statistically significant higher abundance in children with ASD compared to their control groups. Specifically, at phylum level: Proteobacteria (Coretti et al., 2018) were found to have statistically significant higher abundance in children with ASD compared to their control groups. At family level: Lactobacillaceae, Enterococcaceae, Erysipelotrichaceae and Desulfovibrionaceae (Pulikkan et al., 2018), Peptostreptococcaceae (Berding and Donovan, 2018), Bacteroidaceae, Lachnospiraceae and Ruminococcaceae (Rose et al., 2018), and presumptive Enterobacteriaceae (De Angelis et al., 2013) were found to have statistically significant higher abundance in children with ASD compared to their control groups. At genus level: Porphyromonas, presumptive Bacteroides, Porphyromonas and Prevotella, Caloromator, Sarcina, Anaerofilum, presumptive Pseudomonas and Aeromonas, and Shigella (De Angelis et al., 2013), Ruminococcus and Lachnospira (Coretti et al., 2018), Collinsella (Strati et al., 2017), Mitsuokella and Megasphaera (Pulikkan et al., 2018), Burkholderia (Kushak et al., 2017), Roseburia (De Angelis et al., 2013; Berding and Donovan, 2018; Coretti et al., 2018), Peptostreptococcus and Ralstonia (Kushak et al., 2017), and Candida (Iovene et al., 2017; Strati et al., 2017) were found to have statistically significant higher abundance in children with ASD compared to their control groups. At species level: Bilophila wadsworthia, Flavonifractor plautii, Roseburia intestinalis, Lachnoclostridium boltae, Lachnoclostridium hathewayi, Oscillospira valericigenes, Clostridium lituseburense and Clostridium aldenense (Luna et al., 2017), Ruminococcus gnavus and Ruminococcus torques (Wang et al., 2013), Lactobacillus ruminis (Pulikkan et al., 2018), and Akkermansia muciniphila (De Angelis et 
al., 2013) were found to have statistically significant higher abundance in children with ASD compared to their control groups.

\section{Low abundance of some gut microbes in ASD}

Three bacterial phyla, four bacterial families, twenty-two bacterial genera, one presumptive bacterial genus, two presumptive bacterial genera groups, and five bacterial species were found to have statistically significant lower abundance in children with ASD compared to their control groups. Specifically, at phylum level: Fusobacteria, Verrumicrobia (De Angelis et al., 2013), and Actinobacteria (Coretti et al., 2018). At family level: Rikenellaceae (Berding and Donovan, 2018), Actinomycetaceae, Streptococcaceae and Gemellaceae (Coretti et al., 2018). At genus level: Fusobacterium, Eubacterium, Subdoligranulum, Enterococcus, Turicibacter, presumptive Staphylococcus, presumptive Streptococcus and Lactococcus, and presumptive Enterococcus and Lactobacillus (De Angelis et al., 2013), Alistipes (Strati et al., 2017), Dialister and Bilophila (Strati et al., 2017; Berding and Donovan, 2018), Eggerthella (Coretti et al., 2018), Peptoniphilus, Parvimonas, Bulleida and Escherichia (Zhang et al., 2018), Haemophilus (Kang et al., 2018), Neisseria (Kushak et al., 2017), Coprococcus (Kang et al., 2013; Coretti et al., 2018), Veillonella (Strati et al., 2017; Zhang et al., 2018), Prevotella (De Angelis et al., 2013; Kang et al., 2013; Kushak et al., 2017), Streptococcus (De Angelis et al., 2013; Inoue et al., 2016; Kushak et al., 2017; Coretti et al., 2018; Zhang et al., 2018), Butyricimonas and Butyrivibrio (Berding and 
Donovan, 2018), and Devosia (Kushak et al., 2017). At species level: Bacteroides vulgatus, unidentified Bacteroides and Escherichia coli (Kushak et al., 2017), Prevotella copri and Haemophilus parainfluenzae (Kang et al., 2018).

\section{Sample characteristics and other parameters studied}

Among the 21 articles found in the present systematic review, none of them studied the communities of viruses and protozoa. Only two articles reported data about Fungi community (Iovene et al., 2017; Strati et al., 2017).

Place where the sample was taken

Three articles analyzed the GM in biopsies taken from the GI tract (Williams et al., 2012; Kushak et al., 2017; Luna et al., 2017), while the rest of the articles analyzed the GM in feces samples.

\section{Bacterial detection methods}

Seventeen articles used culture-independent methods (16S rRNA pyrosequencing of bacterial genes or PCR-based detection), three articles used culture-dependent methods (Finegold et al., 2017; Iovene et al., 2017; Gora et al., 2018), and one article used both methods (De Angelis et al., 2013). In this sense, De Angelis et al. (2013) used culturedependent and culture-independent methods, finding no differences in the abundance of some gut microbes between both methods as reported elsewhere (Alinovi et al., 2009). The case of Candida was similar, as higher abundance of this bacterial genus was found in Italian children with ASD using culture-dependent (Iovene et al., 2017) and culture-independent 
(Strati et al., 2017) methods. However, in the case of Lactobacillus and Clostridium the results obtained by different authors using both methods were contradictory.

Among the eighteen articles using culture-independent methods, three used qPCR (Wang et al., 2013; Tomova et al., 2015; Shaaban et al., 2017), three used both qPCR and pyrosequencing of the 16S rRNA gene bacterial (Williams et al., 2012; Kang et al., 2013; Son et al., 2015) and the remaining 12 articles used only pyrosequencing of the 16S rRNA gene bacterial. Among the 15 articles using pyrosequencing of the 16S rRNA gene bacterial method, five used pyrosequencing of the 16S rRNA gene bacterial ( $\mathrm{V}_{3}-\mathrm{V}_{4}$ region) (Inoue et al., 2016; Berding and Donovan, 2018; Coretti et al., 2018; Rose et al., 2018; Zhang et al., 2018), three used pyrosequencing of the $16 \mathrm{~S}$ rRNA gene bacterial $\left(\mathrm{V}_{1}-\mathrm{V}_{3}\right.$ region) (Gondalia et al., 2012; De Angelis et al., 2013; Kushak et al., 2017), two used pyrosequencing of the 16S rRNA gene bacterial ( $\mathrm{V}_{2}-\mathrm{V}_{3}$ region) (Kang et al., 2013; Kang et al., 2018), one used pyrosequencing of the 16S rRNA gene bacterial ( $\mathrm{V}_{3}-\mathrm{V}_{5}$ region) (Strati et al., 2017), one used pyrosequencing of the 16S rRNA gene bacterial ( $\mathrm{V}_{1}-\mathrm{V}_{2}$ and $\mathrm{V}_{1}-\mathrm{V}_{3}$ region) (Son et al., 2015), one used pyrosequencing of the $16 \mathrm{~S}$ rRNA gene bacterial $\left(\mathrm{V}_{1}-\mathrm{V}_{3}\right.$ and $\mathrm{V}_{4}$ region) (Luna et al., 2017), one used pyrosequencing of the 16S rRNA gene bacterial ( $V_{2}$ region) (Williams et al., 2012) and one used pyrosequencing of the 16S rRNA gene bacterial (V3 region) (Pulikkan et al., 2018). Taking into account the five articles using pyrosequencing of the 16S rRNA gene bacterial ( $\mathrm{V}_{3}-\mathrm{V}_{4}$ region) method, higher abundance of Bacteroidetes and Roseburia and lower abundance of Actinomyces and Streptococcus were found in children with ASD compared to HC by more than one article. However, Firmicutes, Coriobacteriaceae, Blautia and 
Faecalibacterium showed abundance discrepancies in children with ASD compared to HC in more than one article.

\section{Nature of control groups}

Neurotypical (NT) children were used as the control group in four articles (Kang et al., 2013; Luna et al., 2017; Strati et al., 2017; Kang et al., 2018), NT siblings were used as the control group in two articles (Gondalia et al., 2012; Son et al., 2015), both NT siblings and healthy children were used as control groups in one article (Wang et al., 2013), both healthy siblings and healthy children were used as control groups in one article (Tomova et al., 2015), both Pervasive Developmental Disorder Not Otherwise Specified (PDD-NOS) and healthy siblings were used as control groups in one article (De Angelis et al., 2013), one article used healthy siblings as the control group (Pulikkan et al., 2018), and healthy children were used as the control group in the rest of the articles. Of note, NT children are defined as individuals without neurological, medical, or psychiatric diagnoses (Hamilton et al., 2016), and they can also be referred to as the healthy children group. However, differences in gut microbe abundance can occur when siblings or unrelated people are used as a control group (Krajmalnik-Brown et al., 2015). Any child could be colonized by oro-fecal transmission and, if predisposed with a defective immune system, an abnormal GM related to antimicrobials and other factors such as genetics, could lead to the development of ASD (Finegold et al., 2010).

Nationalities of the children studied 
The children with ASD studied were from 9 different nationalities: American (Williams et al., 2012; Kang et al., 2013; Son et al., 2015; Finegold et al., 2017; Kushak et al., 2017; Luna et al., 2017; Berding and Donovan, 2018; Kang et al., 2018; Rose et al., 2018), Australian (Gondalia et al., 2012; Wang et al., 2013), Chinese (Zhang et al., 2018), Egyptian (Shaaban et al., 2017), Indian (Pulikkan et al., 2018), Italian (De Angelis et al., 2013; Iovene et al., 2017; Strati et al., 2017; Coretti et al., 2018), Japanese (Inoue et al., 2016), Polish (Gora et al., 2018) and Slovakian (Tomova et al., 2015). The difference in the nationalities of the children with ASD is also a factor to be taken into account and it is important to consider that there are differences in bacteria prevalence according to the country due to cultural and dietary aspects, among other factors (Lindström and Langenheder, 2012). In this sense, Firmicutes dominate the GM of the general European population (Tomova et al., 2015), and general American and Chinese communities showed high abundances of Firmicutes and Bacteroidetes, respectively (Gupta et al., 2017). In addition, inter-individual and regional differences have been also reported in the general population (Hill et al., 2010; Cerdo et al., 2018) and there is a lack of studies testing the effects of the Mediterranean-style diet on ASD.

\section{Presence of functional gastrointestinal disorders}

No functional gastrointestinal disorders (FGID) were reported in five articles (De Angelis et al., 2013; Inoue et al., 2016; Shaaban et al., 2017; Berding and Donovan, 2018; Coretti et al., 2018). Although there is a greater prevalence of GI symptoms in ASD 
(McElhanon et al., 2014; Martínez-González and Andreo-Martínez, 2019) there are studies reporting no FGID, as some authors excluded children with ASD and FGID in their studies (De Angelis et al., 2013; Strati et al., 2017; Berding and Donovan, 2018).

\section{Diagnosis of ASD severity and intellectual disability}

Two articles reported the ASD severity of the children (Iovene et al., 2017; Pulikkan et al., 2018) and neither of these articles indicated whether children with ASD had been diagnosed with an intellectual disability, which is a very important aspect that influences adaptive ASD behavior (Inada et al., 2015).

\section{Higher or lower abundance of gut microbes in ASD}

One bacterial genus (Roseburia) and one fungi genus (Candida) were found to have statistically significant higher abundance in children with ASD by more than one article (Table 1). Roseburia and Coprococcus genera (De Angelis et al., 2013) together with some ASD-associated bacteria such as the Clostridia class, and Bacteroides and Desulfovibrio genera (MacFabe, 2012; MacFabe, 2015) were described as capable of degrading starch and fermenting other carbohydrates to synthesize SCFA. Propionic acid and other SCFAs are mainly produced by active microbiota fermentation of vegetable fiber and/or dietary carbohydrates in the cecum (Nankova et al., 2014; Frye et al., 2016; Rose et al., 2017; Maji et al., 2018). Propionic acid and butyrate can act as colonocytes and mitochondrial fuels, and electrolyte absorption by colon mucosa with anti-inflammatory properties (De Angelis et al., 2013). Propionic acid and butyrate have differential modulatory effects on mitochondrial and 
cellular function which can be complex and concentration-dependent (Frye et al., 2015) and can include T-cell function modulation and cytokine production (Rose et al., 2017). Indeed, SCFA can disrupt cellular physiology in order to cause FGID associated with ASD such as non-specific inflammation and dysmotility (Kang et al., 2017; Rose et al., 2017). In addition, butyrate can promote the synthesis of mucin and enhance intestinal tight junction integrity (Zhang et al., 2018). Many genera of the Lachnospiraceae family, such as Roseburia and Dorea, which were found to have higher abundance in Italian children with ASD, have a very poor capacity to degrade free amino acids (FAAs) (De Angelis et al., 2013). It has been reported that FAAs fecal level increases in children with ASD, especially glutamate (Glu). Some FAAs, particularly Glu, also act as neurotransmitters in the central nervous system, and a Glu excess can lead to neuronal death, so Glu has an important role in the pathophysiology of some neuropsychiatric disorders, including ASD (Won et al., 2012). On the other hand, Candida albicans was the most frequently identified Candida species in the work of Iovene et al. (2017). In fact, some studies have pointed out that high abundance of Candida albicans can cause less carbohydrate and mineral absorption, and generate higher toxin levels that could contribute to ASD behaviors (Kantarcioglu et al., 2016). Other authors hypothesized that some Lactobacillus species can modulate the immunological responses to Candida in the GI tract by providing tryptophan-derived aryl hydrocarbon receptor ligands that stimulate the immune system, principally IL-C3 cells, to produce IL-22. Together with IL-17, IL-22 prevents the excessive proliferation of Candida and other fungal commensals (Zelante et al., 2013; Strati et al., 2017). In other words, IL-22 allows for survival of mixed microbial communities yet provides a pivotal innate antifungal resistance to Candida and mucosal 
protection from inflammation (Zelante et al., 2013). In this sense, it is possible that ASD dysbiosis may lead to a Candida population expansion, preventing complete bacterial community structural restoration, as can be observed by the lower abundance of Lactobacillus found in Italian children with ASD and FGID compared to their HC group (Iovene et al., 2017),. However, higher abundance of Lactobacillus was also found in Italian children with ASD compared to their NT group (Strati et al., 2017). In conclusion, there is a clear lack of investigation of the whole Fungi kingdom in children with ASD and there is still little known about the influence of Candida and other types of fungi on both GI and ASD symptoms (Andreo-Martínez et al., 2019).

In addition, six bacterial genera (Prevotella, Dialister, Bilophila, Veillonella, Streptococcus and Coprococcus) were found by more than one article to have statistically significant lower abundance in children with ASD (Table 1).

Lower abundance of Prevotella has been found in feces of Italian children with ASD compared to their sibling group (De Angelis et al., 2013), in feces of American children with ASD compared to their NT group (Kang et al., 2013), and in duodenal biopsy samples from the second part of the duodenum of American children with ASD compared to their HC group (Kushak et al., 2017). As can be observed, similar results were achieved by comparing two different nationalities, two different control groups and two different places where the sample was taken.

It is believed that the presence of Prevotella and other Bacteroidetes are associated with colon health and ASD manifestations may have their origin in a dysbiosis where Prevotella decreases and Sutterella increases (Ding et al., 2017). In this sense, the lower 
abundance of Prevotella found in American children with ASD was associated with the presence of ASD symptoms instead of FGID (Kang et al., 2013). These authors found no correlation in a later work (Kang et al., 2018), although they found that FGID were significantly more severe in American children with ASD compared to their NT group. As Prevotella is just one genus of the GM that is very diverse and has a tendency to coexist with a complex collection of other bacterial species, Krajmalnik-Brown et al. (2015) tried to find an explanation about the lower abundance of Prevotella in American children with ASD compared to both Malawian and Venezuelan children with ASD. They found that Prevotella may act as an indicator of Westernization and this change could also be framing an altered immune system, but their results were not conclusive. Finally, Desulfovibrio works synergistically with Prevotella to degrade mucin and Desulfovibrio, Prevotella, and Oscillibacter can utilize microbial exopolysaccharides synthesized by Bifidobacterium to produce SCFA in the GI tract (Kang et al., 2013). In this sense, the lower abundance of Prevotella can decrease the SCFA level in the GI tract of children with ASD.

Veillonella was less abundant in Chinese (Zhang et al., 2018) and Italian (Strati et al., 2017) children with ASD compared to their HC and NT groups, respectively (Table 1).

Different nationalities and similar control groups showed no differences in this bacteria genus. In addition, Coprococcus, Veillonellaceae and Enterococcaceae, together with Prevotella, are intriguingly versatile bacteria that degrade and/or ferment carbohydrates, suggesting that differences in microbial composition (especially in Veillonella) of children with ASD may be a consequence of diet (Kang et al., 2013; Pulikkan et al., 2018). Then, a lower abundance of Veillonella may disturb the fermentation of lactate in children with ASD, 
as this bacterial genus is capable of fermenting lactate (Zhang et al., 2018). As Dialister is a bacteria belonging to the Veillonellaceae family, the aforementioned statement for Veillonella could be also valid for Dialister, as this bacterial genus also showed lower abundance in American (Berding and Donovan, 2018) and Italian (Strati et al., 2017) children with ASD compared to HC. Further, lower abundance of Dialister has been statically correlated with nutritional intake. Specifically, children with ASD eating 20 foods or less in their diet had lower intakes of pectin, vitamin C, niacin, vitamin B6, folate, and selenium, but higher intakes of added sugars (Berding and Donovan, 2018). Streptococcus was found to be less abundant in duodenal biopsy samples from the second part of the duodenum of American children with ASD compared to their HC group (Kushak et al., 2017), in feces of Chinese (Zhang et al., 2018) and Japanese (Inoue et al., 2016) children with ASD compared to their HC groups, respectively, and in feces of Italian children with ASD compared to their HC (Coretti et al., 2018) and siblings (De Angelis et al., 2013) groups, respectively, with Streptococcus and Enterococcus being the dominant genera of the Bacilli class in the work of De Angelis et al. (2013). Those results are similar even when comparing four different nationalities, two different control groups and two different places where the sample was taken.

Streptococcus together with Lactobacillus, Bifidobacterium and Lactococcus produce lactate (Zhang et al., 2018). It is known that ASD patients show high levels of lactate (Rossignol and Frye, 2011), suggesting an increase in glycolysis through the phenomenon of aerobic glycolysis in ASD since the dysregulation of this balance has been proposed as a potential cause of ASD (Vallée and Vallée, 2018). At this point, we cannot confirm that the 
increase in lactate in people with ASD can be attributed solely to the GM since, as seen below, there is still no consensus regarding the abundance of certain lactate-producing bacteria such as Lactobacillus or Bifidobacterium.

American children with ASD compared to their NT group (Kang et al., 2013) and Italian children with ASD compared to their HC group (Coretti et al., 2018) showed lower abundance of Coprococcus (Table 1). In this case, two different nationalities and similar control groups coincided in low abundances of this bacterial genus.

Coprococcus comes was positively correlated with aerophagia and Coprococcus catus was negatively correlated with abdominal migraine (Luna et al., 2017), showing the role played by some Coprococcus species in FGID. Finally, as discussed before, Coprococcus also produces SCFA, suggesting that the unusual diet patterns observed in ASD children may be a possible influence (Kang et al., 2013).

Bilophila is a sulfite-reducing and hydrogen sulfide-producing bacteria in the human GI tract which is usually difficult to detect in healthy individuals. Increased numbers of Bilophila in GM induce systemic inflammation and thus contributes to the onset of the metabolic disorders (Feng et al., 2017). The present systematic review found lower abundance of Bilophila in American (Berding and Donovan, 2018) and Italian (Strati et al., 2017) children with ASD compared to HC, therefore, further research is needed regarding the implications of this bacterial genus in ASD. Regarding the Bacteroidetes/Firmicutes ratio in the GI tract of children with ASD, it is characterized by a lower Bacteroidetes/Firmicutes ratio in Italian, Slovakian, and Indian children with ASD compared to their heterogenous control groups (De Angelis et al., 2013; Tomova et al., 2015; Strati et al., 2017; Pulikkan et 
al., 2018). However, according to Coretti et al. (2018) and Zhang et al. (2018), the Bacteroidetes/Firmicutes ratio in Italian and Chinese children with ASD, respectively, was higher than their HC groups. As discussed before, different nationalities, control groups, the place where the sample was taken or bacterial detection methods can lead to contradictory results. In addition, Tomova et al. (2015) hypothesized that the possible reasons for contradictory results in different studies can be due to participants' age (younger people’s GM contain proportionally fewer Bacteroidetes), GI problems in HC, GI tract level where sample was taken, or geographical area. Therefore, for the correct interpretation of GM's role in ASD, etiopathogenesis can be important to compare matching homogeneous groups.

\section{Possible reasons of the differences found in GM of ASD}

The differences found in GM of children with ASD can be attributed to ASD heterology, small sample sizes, different places where the sample were taken, different bacterial identification methods, different nationalities, inter-individual differences, antibiotic use, malnutrition, dietary habits, age of participants and nature of control groups, prebiotics and probiotics used, and FGID presence, among others. For example, it has been reported that GM communities of fecal samples are similar to luminal communities; however, significantly higher abundances of some gut microbes that preferentially adhere to the mucosa, such as Lactobacillus, compared to fecal samples have been found. Therefore, the place where the sample were taken can be relevant for mammalian physiology, as bacterial communities display differences between anatomical locations (Hill et al., 2010; Durbán et al., 2012; Martínez-González and Andreo-Martínez, 2019). Regarding bacterial detection methods: on 
the one hand, absolute cell abundances of culturable living microbes can be quantified using culture-dependent methods, although the number of microorganisms detected is limited and this method requires some days to obtain results. On the other hand, the use of cultureindependent methods has increased in recent years due to the fact that they can readily identify a large proportion of the bacterial diversity and they give fast results. In addition, amplification bias in heterogeneous mixtures may occur due to differences in genomic sequences at primer sites, 16S rRNA copy number, different bioinformatic analysis methods and guanine-cytosine content, such that the read counts can be correlated semi-quantitatively with the relative abundance of bacterial species (Gondalia et al., 2012; Salipante et al., 2013; Zapka et al., 2017). Therefore, future studies should use similar bacterial detection methods in order to minimize these biases, taking into account the fact that culture-independent methods are relatively new in comparison with culture-dependent methods and they are still developing and not yet standardized (Zapka et al., 2017). Thus, future microbial technological developments should combine omics data with phenotypic information to invoke and control specific phenotypes in the microbiome (De Vrieze and Boon, 2018). Of note, there are still discrepancies in the abundance of some bacteria using the same bacterial detection method, as discussed in section 3.2.2. In addition, one explanation regarding the differences in gut microbe's abundance when siblings or unrelated people are used as a control group could be that the children of both samples intake a similar diet, or the possible fecal bacteria transmission from children with ASD to their siblings (multiple ASD cases are common in families), playmates, friends, etc. resulting in similar bacterial abundance (Tomova et al., 2015). 


\section{Concluding remarks}

At this point, there is no consensus about a GM profile of children with ASD and further research is needed. In addition, an important absence in the psychometric analysis of the relationship between the severity of behavioral ASD symptoms and bacterial abundance and FGID has been found. Similarly, none of the studies indicate whether children with ASD have been diagnosed with an intellectual disability.

Therefore, the results of the present systematic review encourage the need to initiate new multicenter studies on the impact of bacterial components of GM on: gastrointestinal physiology, neurophysiology, metabolomic and behavior of children with ASD. We consider that ASD has a wide phenotypic variability, so future studies should consider the genetic, phenotypic and behavioral antecedents in a more integral and interdisciplinary way. In addition, we consider it of great importance that future studies classify ASD groups according to the severity of ASD and intellectual disability. Finally, we argue that future research should homogenize statistical analysis in order to develop meta-analytical studies on the GM involved in ASD.

\section{Author Contributions}

Pedro Andreo-Martínez and Agustín Ernesto Martínez-González conceived and designed the systematic review. Pedro Andreo-Martínez and Nuria Garcia-Martínez carried out the 
systematic review process. Pedro Andreo-Martínez, Nuria García-Martínez and Elvira Pilar Sánchez-Samper wrote the manuscript. Agustín Ernesto Martínez-González edited the manuscript and all the authors approved the final version of the manuscript.

\section{Funding}

This research did not receive any specific grant from funding agencies in the public, commercial, or not-for-profit sectors.

\section{Compliance with Ethical Standards}

This article does not contain any studies with human participants or animals performed by any of the authors.

\section{Conflicts of interest}

The authors declare that they have no conflict of interest.

\section{Acknowledgements}

The authors would like to acknowledge Ms. Seonaid McNabb and Mr. Andy McCarthy for their English revision. We appreciate the initial contact and kindness of Dr. Derrick MacFabe (Kilee Patchell-Evans Autism Research Group, London, Ontario, Canada). 


\section{References}

Alinovi, C.A., Ward, M.P., Lin, T.L., Moore, G.E., and Wu, C.C. (2009) Real-time PCR, compared to liquid and solid culture media and ELISA, for the detection of Mycobacterium avium ssp. paratuberculosis. Vet Microbiol 136: 177-179.

Andreo-Martínez, P., García-Martínez, N., Quesada-Medina, J., Sánchez-Samper, E.P., and Martínez-González, A.E. (2019) Candida spp. en la microbiota intestinal de las personas con autismo: revisión sistemática. Rev Neurol 68: 1-6.

Arumugam, M., Raes, J., Pelletier, E., Le Paslier, D., Yamada, T., Mende, D.R. et al. (2011) Enterotypes of the human gut microbiome. Nature 473: 174.

Berding, K., and Donovan, S.M. (2018) Diet Can Impact Microbiota Composition in Children With Autism Spectrum Disorder. Frontiers in neuroscience 12: 515-515.

Bonnet-Brilhault, F., Rajerison, T.A., Paillet, C., Guimard-Brunault, M., Saby, A., Ponson, L. et al. (2018) Autism is a prenatal disorder: Evidence from late gestation brain overgrowth. Autism Res 11: 1635-1642.

Borre, Y.E., O'Keeffe, G.W., Clarke, G., Stanton, C., Dinan, T.G., and Cryan, J.F. (2014) Microbiota and neurodevelopmental windows: implications for brain disorders. Trends $\mathrm{Mol}$ Med 20: 509-518.

Buie, T. (2015) Potential Etiologic Factors of Microbiome Disruption in Autism. Clin Ther 37: 976-983.

Cao, X., Lin, P., Jiang, P., and Li, C. (2013) Characteristics of the gastrointestinal microbiome in children with autism spectrum disorder: a systematic review. Shanghai Arch Psychiatry 25: 342-353.

Cerdo, T., Ruiz, A., Acuna, I., Jauregui, R., Jehmlich, N., Haange, S.B. et al. (2018) Gut microbial functional maturation and succession during human early life. Environ Microbiol 20: $2160-2177$.

Coretti, L., Paparo, L., Riccio, M.P., Amato, F., Cuomo, M., Natale, A. et al. (2018) Gut Microbiota Features in Young Children With Autism Spectrum Disorders. Front Microbiol 9.

Danchin, A. (2018) Bacteria in the ageing gut: did the taming of fire promote a long human lifespan? Environ Microbiol 20: 1966-1987. 
De Angelis, M., Francavilla, R., Piccolo, M., De Giacomo, A., and Gobbetti, M. (2015) Autism spectrum disorders and intestinal microbiota. Gut Microbes 6: 207-213.

De Angelis, M., Piccolo, M., Vannini, L., Siragusa, S., De Giacomo, A., Serrazzanetti, D.I. et al. (2013) Fecal microbiota and metabolome of children with autism and pervasive developmental disorder not otherwise specified. PLoS One 8: e76993.

De Vrieze, J., and Boon, N. (2018) Taking the technical microbiome into the next decade. Environ Microbiol 20: 1991-2000.

Diaz Heijtz, R. (2016) Fetal, neonatal, and infant microbiome: Perturbations and subsequent effects on brain development and behavior. Semin Fetal Neonatal Med 21: 410-417.

Ding, H.T., Taur, Y., and Walkup, J.T. (2017) Gut Microbiota and Autism: Key Concepts and Findings. J Autism Dev Disord 47: 480-489.

Durbán, A., Abellán, J.J., Jiménez-Hernández, N., Salgado, P., Ponce, M., Ponce, J. et al. (2012) Structural alterations of faecal and mucosa-associated bacterial communities in irritable bowel syndrome. Environmental Microbiology Reports 4: 242-247.

Feng, Z., Long, W., Hao, B., Ding, D., Ma, X., Zhao, L., and Pang, X. (2017) A human stoolderived Bilophila wadsworthia strain caused systemic inflammation in specific-pathogen-free mice. Gut Pathogens 9: 59.

Ferguson, B.J., Marler, S., Altstein, L.L., Lee, E.B., Mazurek, M.O., McLaughlin, A. et al. (2016) Associations between cytokines, endocrine stress response, and gastrointestinal symptoms in autism spectrum disorder. Brain, Behav, Immun 58: 57-62.

Finegold, S.M., Summanen, P.H., Downes, J., Corbett, K., and Komoriya, T. (2017) Detection of Clostridium perfringens toxin genes in the gut microbiota of autistic children. Anaerobe 45: 133-137.

Finegold, S.M., Dowd, S.E., Gontcharova, V., Liu, C., Henley, K.E., Wolcott, R.D. et al. (2010) Pyrosequencing study of fecal microflora of autistic and control children. Anaerobe 16: 444-453.

Frye, R.E., Rose, S., Slattery, J., and MacFabe, D.F. (2015) Gastrointestinal dysfunction in autism spectrum disorder: the role of the mitochondria and the enteric microbiome. Microb Ecol Health Dis 26: 27458. 
Frye, R.E., Nankova, B., Bhattacharyya, S., Rose, S., Bennuri, S.C., and MacFabe, D.F. (2017) Modulation of Immunological Pathways in Autistic and Neurotypical Lymphoblastoid Cell Lines by the Enteric Microbiome Metabolite Propionic Acid. Frontiers in Immunology 8: 1670 .

Frye, R.E., Rose, S., Chacko, J., Wynne, R., Bennuri, S.C., Slattery, J.C. et al. (2016) Modulation of mitochondrial function by the microbiome metabolite propionic acid in autism and control cell lines. Transl Psychiatry 6: e927.

Gondalia, S.V., Palombo, E.A., Knowles, S.R., Cox, S.B., Meyer, D., and Austin, D.W. (2012) Molecular characterisation of gastrointestinal microbiota of children with autism (with and without gastrointestinal dysfunction) and their neurotypical siblings. Autism Res 5: 419427.

Gora, B., Gofron, Z., Grosiak, M., Aptekorz, M., Kazek, B., Kocelak, P. et al. (2018) Toxin profile of fecal Clostridium perfringens strains isolated from children with autism spectrum disorders. Anaerobe 51: 73-77.

Gupta, V.K., Paul, S., and Dutta, C. (2017) Geography, Ethnicity or Subsistence-Specific Variations in Human Microbiome Composition and Diversity. Front Microbiol 8: 1162.

Hamilton, K., Hoogenhout, M., and Malcolm-Smith, S. (2016) Neurocognitive considerations when assessing Theory of Mind in Autism Spectrum Disorder. Journal of Child \& Adolescent Mental Health 28: 233-241.

Hiippala, K., Kainulainen, V., Kalliomaki, M., Arkkila, P., and Satokari, R. (2016) Mucosal Prevalence and Interactions with the Epithelium Indicate Commensalism of Sutterella spp. Front Microbiol 7: 1706.

Hill, D.A., Hoffmann, C., Abt, M.C., Du, Y., Kobuley, D., Kirn, T.J. et al. (2010) Metagenomic analyses reveal antibiotic-induced temporal and spatial changes in intestinal microbiota with associated alterations in immune cell homeostasis. Mucosal Immunol 3: 148158.

Hollister, E.B., Riehle, K., Luna, R.A., Weidler, E.M., Rubio-Gonzales, M., Mistretta, T.-A. et al. (2015) Structure and function of the healthy pre-adolescent pediatric gut microbiome. Microbiome 3: 36-36.

Inada, N., Ito, H., Yasunaga, K., Kuroda, M., Iwanaga, R., Hagiwara, T. et al. (2015) Psychometric properties of the Repetitive Behavior Scale-Revised for individuals with autism spectrum disorder in Japan. Res Autism Spectr Disord 15-16: 60-68. 
Inoue, R., Sakaue, Y., Sawai, C., Sawai, T., Ozeki, M., Romero-Perez, G.A., and Tsukahara, T. (2016) A preliminary investigation on the relationship between gut microbiota and gene expressions in peripheral mononuclear cells of infants with autism spectrum disorders. Biosci, Biotechnol, Biochem 80: 2450-2458.

Iovene, M.R., Bombace, F., Maresca, R., Sapone, A., Iardino, P., Picardi, A. et al. (2017) Intestinal Dysbiosis and Yeast Isolation in Stool of Subjects with Autism Spectrum Disorders. Mycopathologia 182: 349-363.

Kang, D.-W., Ilhan, Z.E., Isern, N.G., Hoyt, D.W., Howsmon, D.P., Shaffer, M. et al. (2018) Differences in fecal microbial metabolites and microbiota of children with autism spectrum disorders. Anaerobe 49: 121-131.

Kang, D.-W., Adams, J.B., Gregory, A.C., Borody, T., Chittick, L., Fasano, A. et al. (2017) Microbiota Transfer Therapy alters gut ecosystem and improves gastrointestinal and autism symptoms: an open-label study. Microbiome 5: 10.

Kang, D.W., Park, J.G., Ilhan, Z.E., Wallstrom, G., Labaer, J., Adams, J.B., and KrajmalnikBrown, R. (2013) Reduced incidence of Prevotella and other fermenters in intestinal microflora of autistic children. PLoS One 8: e68322.

Kantarcioglu, A.S., Kiraz, N., and Aydin, A. (2016) Microbiota-Gut-Brain Axis: Yeast Species Isolated from Stool Samples of Children with Suspected or Diagnosed Autism Spectrum Disorders and In Vitro Susceptibility Against Nystatin and Fluconazole. Mycopathologia 181: 1-7.

Krajmalnik-Brown, R., Lozupone, C., Kang, D.-W., and Adams, J.B. (2015) Gut bacteria in children with autism spectrum disorders: challenges and promise of studying how a complex community influences a complex disease. Microb Ecol Health Dis 26: 26914.

Kumar, H., Lund, R., Laiho, A., Lundelin, K., Ley, R.E., Isolauri, E., and Salminen, S. (2014) Gut microbiota as an epigenetic regulator: pilot study based on whole-genome methylation analysis. MBio 5: e02113-02114.

Kushak, R.I., Winter, H.S., Buie, T.M., Cox, S.B., Phillips, C.D., and Ward, N.L. (2017) Analysis of the Duodenal Microbiome in Autistic Individuals: Association With Carbohydrate Digestion. J Pediatr Gastroenterol Nutr 64: e110-e116.

Letunic, I., and Bork, P. (2016) Interactive tree of life (iTOL) v3: an online tool for the display and annotation of phylogenetic and other trees. Nucleic Acids Res 44: W242-245. 
Li, Q., Han, Y., Dy, A.B.C., and Hagerman, R.J. (2017) The Gut Microbiota and Autism Spectrum Disorders. Frontiers in Cellular Neuroscience 11: 120.

Lindström, E.S., and Langenheder, S. (2012) Local and regional factors influencing bacterial community assembly. Environmental Microbiology Reports 4: 1-9.

Liu, F., Li, J., Wu, F., Zheng, H., Peng, Q., and Zhou, H. (2019) Altered composition and function of intestinal microbiota in autism spectrum disorders: a systematic review. Transl Psychiatry 9: 43.

Luna, R.A., Oezguen, N., Balderas, M., Venkatachalam, A., Runge, J.K., Versalovic, J. et al. (2017) Distinct Microbiome-Neuroimmune Signatures Correlate With Functional Abdominal Pain in Children With Autism Spectrum Disorder. Cellular and molecular gastroenterology and hepatology 3: 218-230.

MacFabe, D.F. (2012) Short-chain fatty acid fermentation products of the gut microbiome: implications in autism spectrum disorders. Microb Ecol Health Dis 23: 19260.

MacFabe, D.F. (2015) Enteric short-chain fatty acids: microbial messengers of metabolism, mitochondria, and mind: implications in autism spectrum disorders. Microb Ecol Health Dis 26: 28177.

Maji, A., Misra, R., Dhakan, D.B., Gupta, V., Mahato, N.K., Saxena, R. et al. (2018) Gut microbiome contributes to impairment of immunity in pulmonary tuberculosis patients by alteration of butyrate and propionate producers. Environ Microbiol 20: 402-419.

Mangiola, F., Ianiro, G., Franceschi, F., Fagiuoli, S., Gasbarrini, G., and Gasbarrini, A. (2016) Gut microbiota in autism and mood disorders. World J Gastroenterol 22: 361-368.

Martínez-González, A.E., and Andreo-Martínez, P. (2019) The Role of Gut Microbiota in Gastrointestinal Symptoms of Children with ASD. Medicina 55: 408.

McElhanon, B.O., McCracken, C., Karpen, S., and Sharp, W.G. (2014) Gastrointestinal Symptoms in Autism Spectrum Disorder: A Meta-analysis. Pediatrics 133: 872-883.

Moher, D., Shamseer, L., Clarke, M., Ghersi, D., Liberati, A., Petticrew, M. et al. (2015) Preferred reporting items for systematic review and meta-analysis protocols (PRISMA-P) 2015 statement. Syst Rev 4: 1.

Nankova, B.B., Agarwal, R., MacFabe, D.F., and La Gamma, E.F. (2014) Enteric bacterial metabolites propionic and butyric acid modulate gene expression, including CREB-dependent 
catecholaminergic neurotransmission, in PC12 cells--possible relevance to autism spectrum disorders. PLoS One 9: e103740.

Ooi, Y.P., Weng, S.J., Kossowsky, J., Gerger, H., and Sung, M. (2017) Oxytocin and Autism Spectrum Disorders: A Systematic Review and Meta-Analysis of Randomized Controlled Trials. Pharmacopsychiatry 50: 5-13.

Pradhan, B., Datzkiw, D., and Aich, P. (2017) Gut microbiota and health: A review with focus on metabolic and immunological disorders and microbial remediation. Biomed Rev 27: $1-18$.

Pulikkan, J., Maji, A., Dhakan, D.B., Saxena, R., Mohan, B., Anto, M.M. et al. (2018) Gut Microbial Dysbiosis in Indian Children with Autism Spectrum Disorders. Microb Ecol.

Rose, D.R., Yang, H., Serena, G., Sturgeon, C., Ma, B., Careaga, M. et al. (2018) Differential immune responses and microbiota profiles in children with autism spectrum disorders and comorbid gastrointestinal symptoms. Brain, Behav, Immun 70: 354-368.

Rose, S., Bennuri, S.C., Murray, K.F., Buie, T., Winter, H., and Frye, R.E. (2017) Mitochondrial dysfunction in the gastrointestinal mucosa of children with autism: A blinded case-control study. PloS One 12: e0186377.

Rossignol, D.A., and Frye, R.E. (2011) Mitochondrial dysfunction in autism spectrum disorders: a systematic review and meta-analysis. Mol Psychiatry 17: 290.

Salipante, S.J., Sengupta, D.J., Rosenthal, C., Costa, G., Spangler, J., Sims, E.H. et al. (2013) Rapid 16S rRNA Next-Generation Sequencing of Polymicrobial Clinical Samples for Diagnosis of Complex Bacterial Infections. PLOS ONE 8: e65226.

Sanchez-Samper, E., Gomez-Gallego, C., Andreo-Martinez, P., Salminen, S., and Ros, G. (2017) Mice gut microbiota programming by using the infant food profile. The effect on growth, gut microbiota and the immune system. Food Funct 8: 3758-3768.

Sandler, R.H., Finegold, S.M., Bolte, E.R., Buchanan, C.P., Maxwell, A.P., Vaisanen, M.L. et al. (2000) Short-term benefit from oral vancomycin treatment of regressive-onset autism. Journal of child neurology 15: 429-435.

Schäffler, H., Herlemann, D.P.R., Alberts, C., Kaschitzki, A., Bodammer, P., Bannert, K. et al. (2016) Mucosa-attached bacterial community in Crohn's disease coheres with the clinical disease activity index. Environmental Microbiology Reports 8: 614-621. 
Sender, R., Fuchs, S., and Milo, R. (2016) Revised Estimates for the Number of Human and Bacteria Cells in the Body. PLoS Biol 14: e1002533.

Shaaban, S.Y., El Gendy, Y.G., Mehanna, N.S., El-Senousy, W.M., El-Feki, H.S.A., Saad, K., and El-Asheer, O.M. (2017) The role of probiotics in children with autism spectrum disorder: A prospective, open-label study. Nutr Neurosci: 1-6.

Son, J.S., Zheng, L.J., Rowehl, L.M., Tian, X., Zhang, Y., Zhu, W. et al. (2015) Comparison of Fecal Microbiota in Children with Autism Spectrum Disorders and Neurotypical Siblings in the Simons Simplex Collection. PLoS One 10: e0137725.

Strati, F., Cavalieri, D., Albanese, D., De Felice, C., Donati, C., Hayek, J. et al. (2017) New evidences on the altered gut microbiota in autism spectrum disorders. Microbiome 5: 24.

Sudo, N., Chida, Y., Aiba, Y., Sonoda, J., Oyama, N., Yu, X.N. et al. (2004) Postnatal microbial colonization programs the hypothalamic-pituitary-adrenal system for stress response in mice. The Journal of Physiology 558: 263-275.

Suzuki, T.A., and Worobey, M. (2014) Geographical variation of human gut microbial composition. Biol Lett 10: 20131037.

Tomova, A., Husarova, V., Lakatosova, S., Bakos, J., Vlkova, B., Babinska, K., and Ostatnikova, D. (2015) Gastrointestinal microbiota in children with autism in Slovakia. Physiol Behav 138: 179-187.

Vallée, A., and Vallée, J.-N. (2018) Warburg effect hypothesis in autism Spectrum disorders. Molecular Brain 11: 1.

Wang, L., Christophersen, C.T., Sorich, M.J., Gerber, J.P., Angley, M.T., and Conlon, M.A. (2011) Low relative abundances of the mucolytic bacterium Akkermansia muciniphila and Bifidobacterium spp. in feces of children with autism. Appl Environ Microbiol 77: 67186721.

Wang, L., Christophersen, C.T., Sorich, M.J., Gerber, J.P., Angley, M.T., and Conlon, M.A. (2013) Increased abundance of Sutterella spp. and Ruminococcus torques in feces of children with autism spectrum disorder. Mol Autism 4: 42.

Williams, B.L., Hornig, M., Parekh, T., and Lipkin, W.I. (2012) Application of Novel PCRBased Methods for Detection, Quantitation, and Phylogenetic Characterization of Sutterella Species in Intestinal Biopsy Samples from Children with Autism and Gastrointestinal Disturbances. mBio 3: e00261-00211. 
Wimberley, T., Agerbo, E., Pedersen, C.B., Dalsgaard, S., Horsdal, H.T., Mortensen, P.B. et al. (2018) Otitis media, antibiotics, and risk of autism spectrum disorder. Autism Res 11: $1432-1440$.

Won, H., Lee, H.-R., Gee, H.Y., Mah, W., Kim, J.-I., Lee, J. et al. (2012) Autistic-like social behaviour in Shank2-mutant mice improved by restoring NMDA receptor function. Nature 486: 261.

Xu, G., Snetselaar, L.G., Jing, J., Liu, B., Strathearn, L., and Bao, W. (2018) Association of food allergy and other allergic conditions with autism spectrum disorder in children. JAMA Network Open 1: e180279.

Yang, C.-J., Tan, H.-P., Yang, F.-Y., Wang, H.-P., Liu, C.-L., He, H.-Z. et al. (2015) The cortisol, serotonin and oxytocin are associated with repetitive behavior in autism spectrum disorder. Res Autism Spectr Disord 18: 12-20.

Zapka, C., Leff, J., Henley, J., Tittl, J., De Nardo, E., Butler, M. et al. (2017) Comparison of Standard Culture-Based Method to Culture-Independent Method for Evaluation of Hygiene Effects on the Hand Microbiome. mBio 8: e00093-00017.

Zelante, T., Iannitti, R.G., Cunha, C., De Luca, A., Giovannini, G., Pieraccini, G. et al. (2013) Tryptophan catabolites from microbiota engage aryl hydrocarbon receptor and balance mucosal reactivity via interleukin-22. Immunity 39: 372-385.

Zhang, M., Ma, W., Zhang, J., He, Y., and Wang, J. (2018) Analysis of gut microbiota profiles and microbe-disease associations in children with autism spectrum disorders in China. Scientific reports 8: 13981-13981.

Table, Figure and supporting information legends

Figure 1. Flowchart showing the process of identifying relevant studies for the present systematic review. 
Figure 2. Phylogenetic map of bacterial populations (Phyla, families, genera and species level) in the ASD.

Note: [A = Williams et al. (2012); B = Gondalia et al. (2012); C = Kang et al. (2013); D = Wang et al. (2013); E = De Angelis et al. (2013); F = Son et al. (2015); G =Tomova et al. (2015); H = Inoue et al. (2016); I = Strati et al. (2017); J = Iovene et al. (2017); K= Luna et al. (2017); L = Finegold et al. (2017); M = Kushak et al. (2017); N = Shaaban et al. (2017); O = Gora et al. (2018); P = Kang et al. (2018); Q = Pulikkan et al. (2018); R = Rose et al. (2018); S = Coretti et al. (2018); T = Zhang et al. (2018); U = Berding and Donovan (2018)].

Table 1. Results of selected articles on ASD and gut microbiota.

Supporting information. Method 


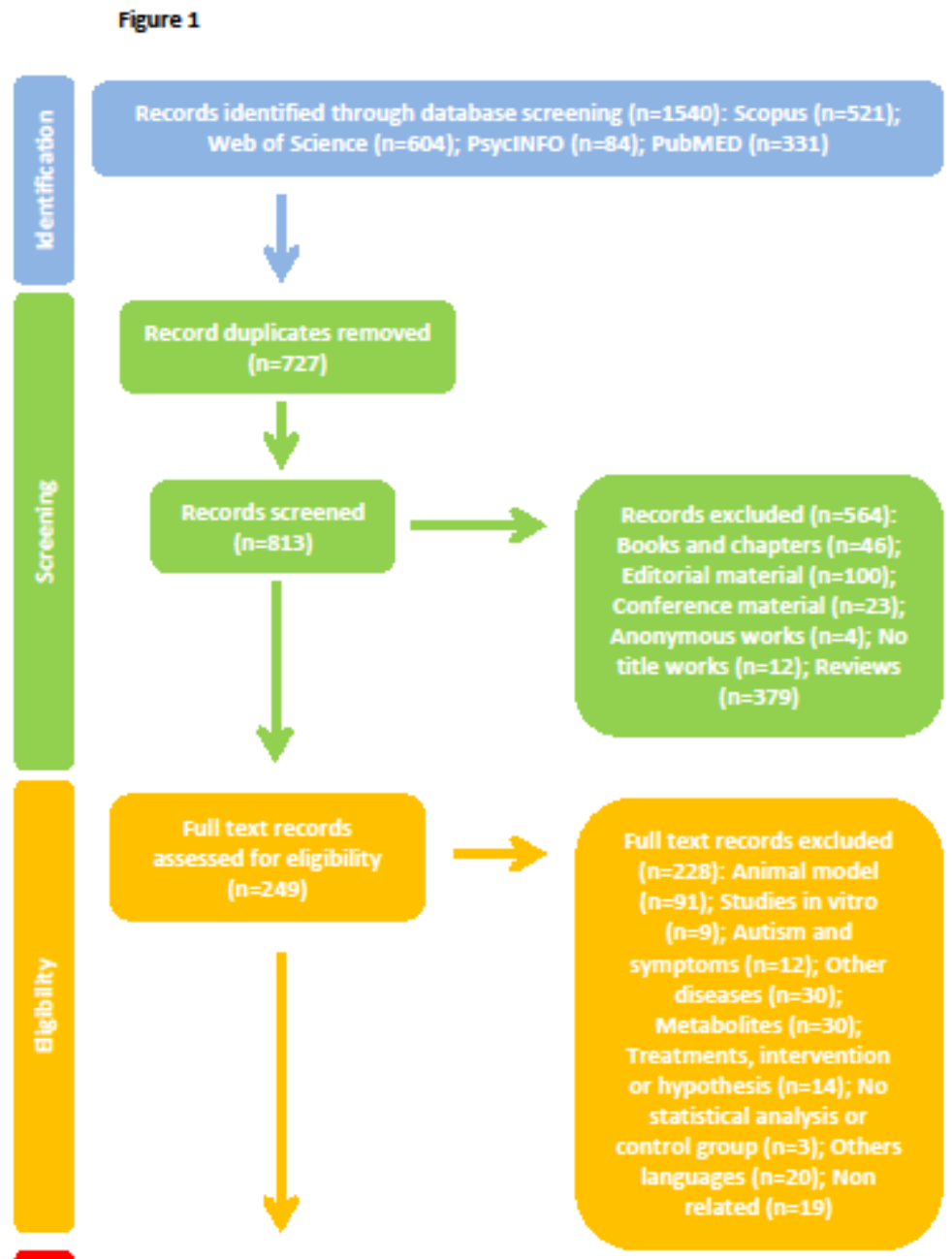

Studies included in this

systematic review ( $n=21$ )

This article is protected by copyright. All rights reserved. 


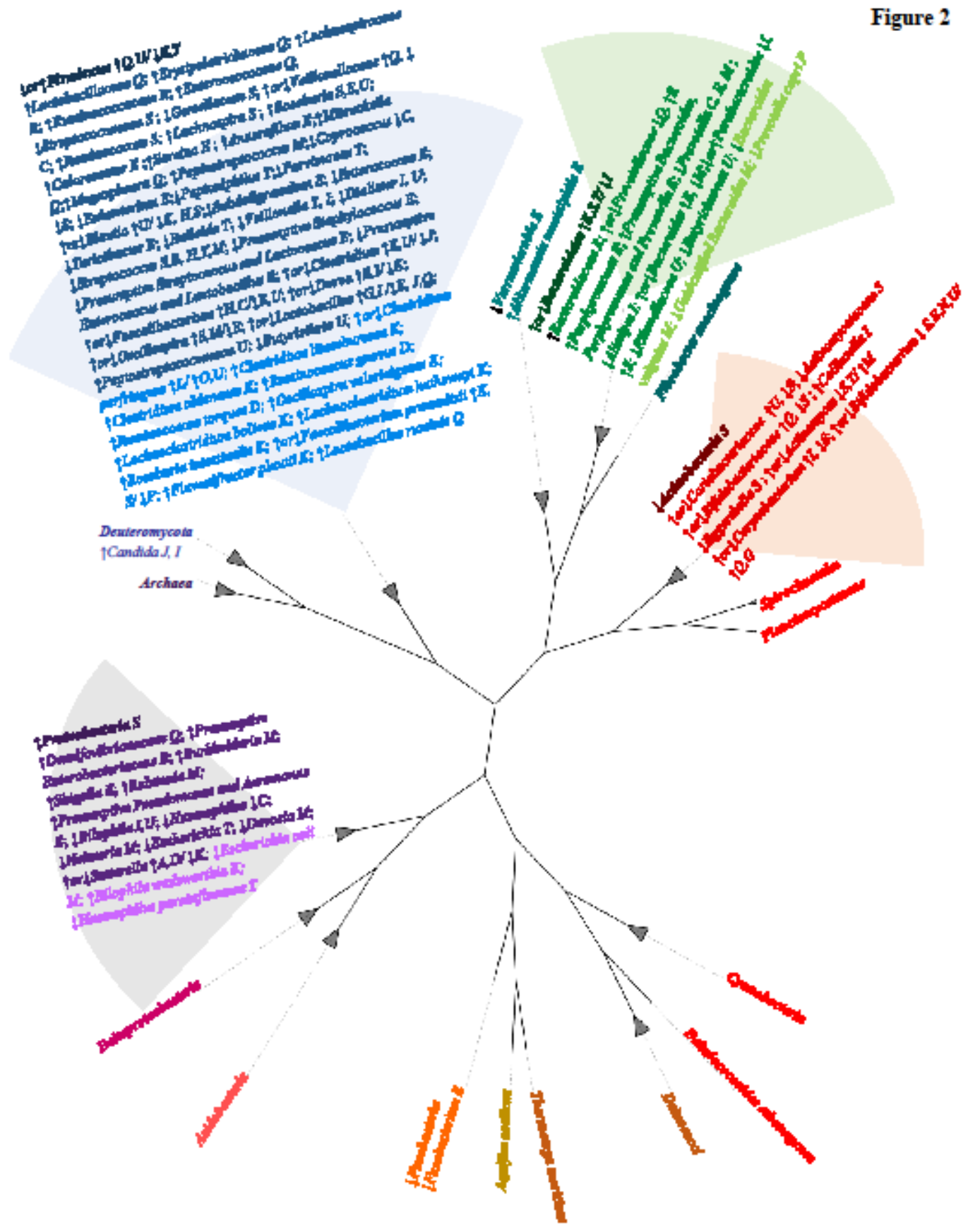

This article is protected by copyright. All rights reserved. 
Table 1. Results of selected studies on ASD and gut microbiota.

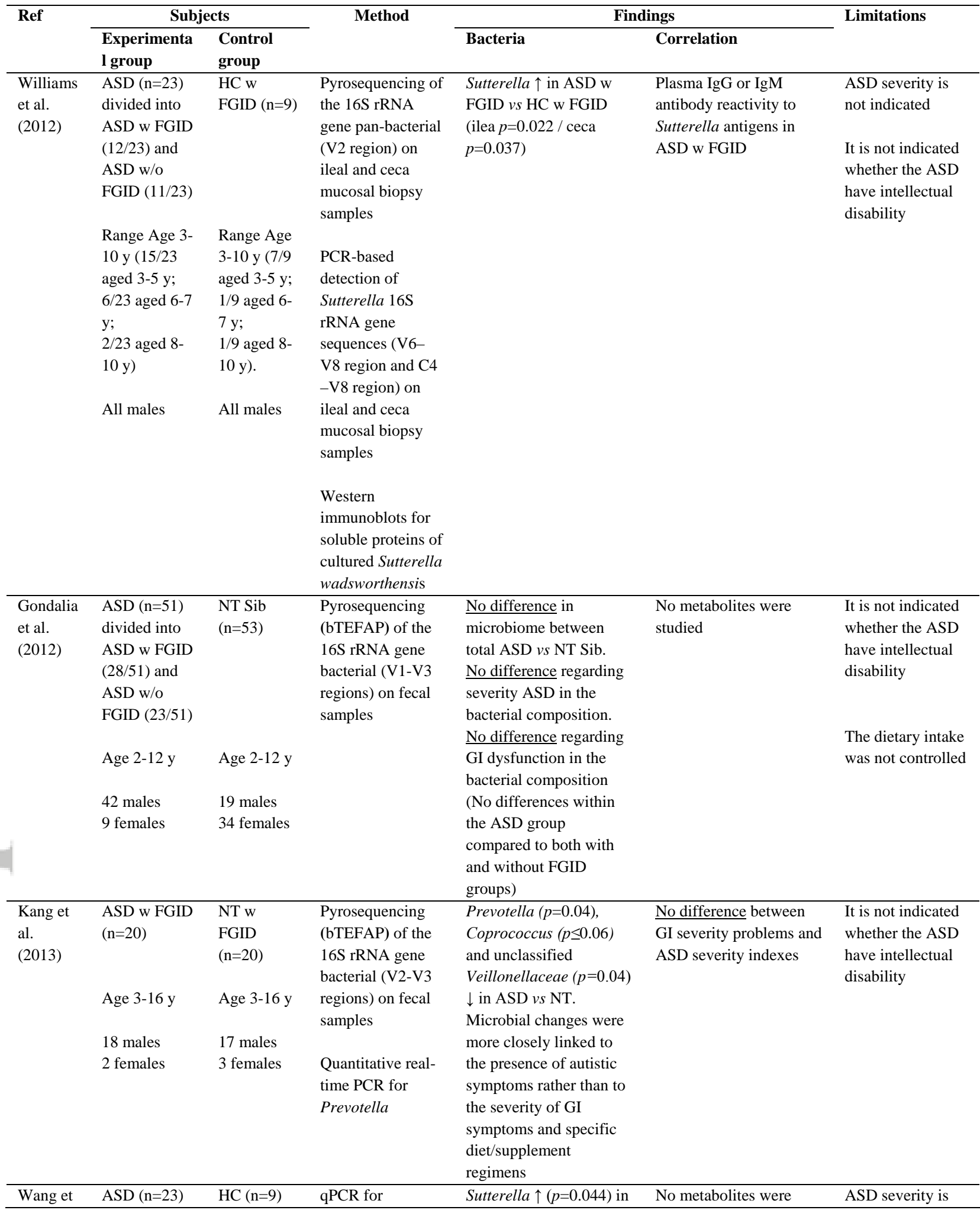




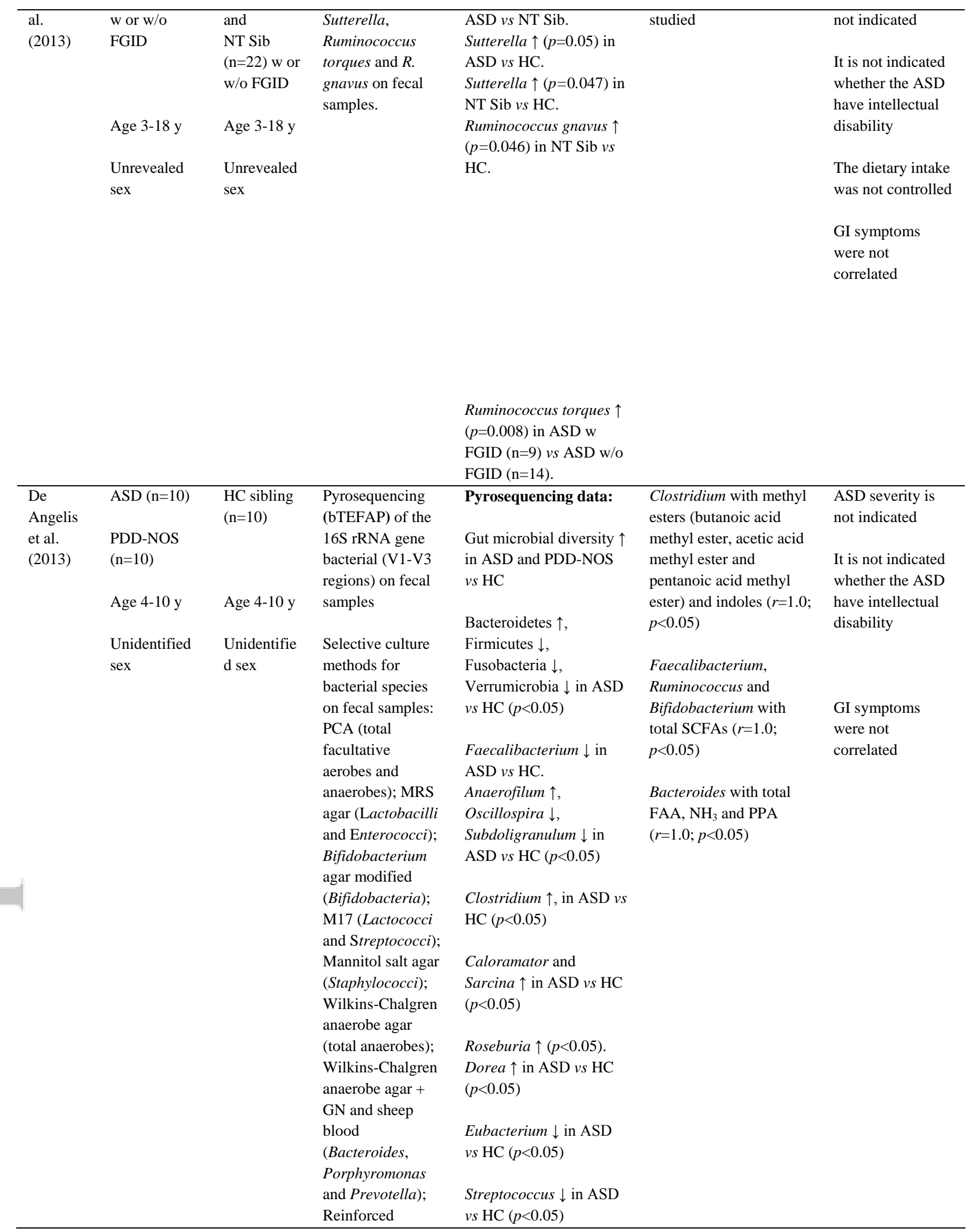




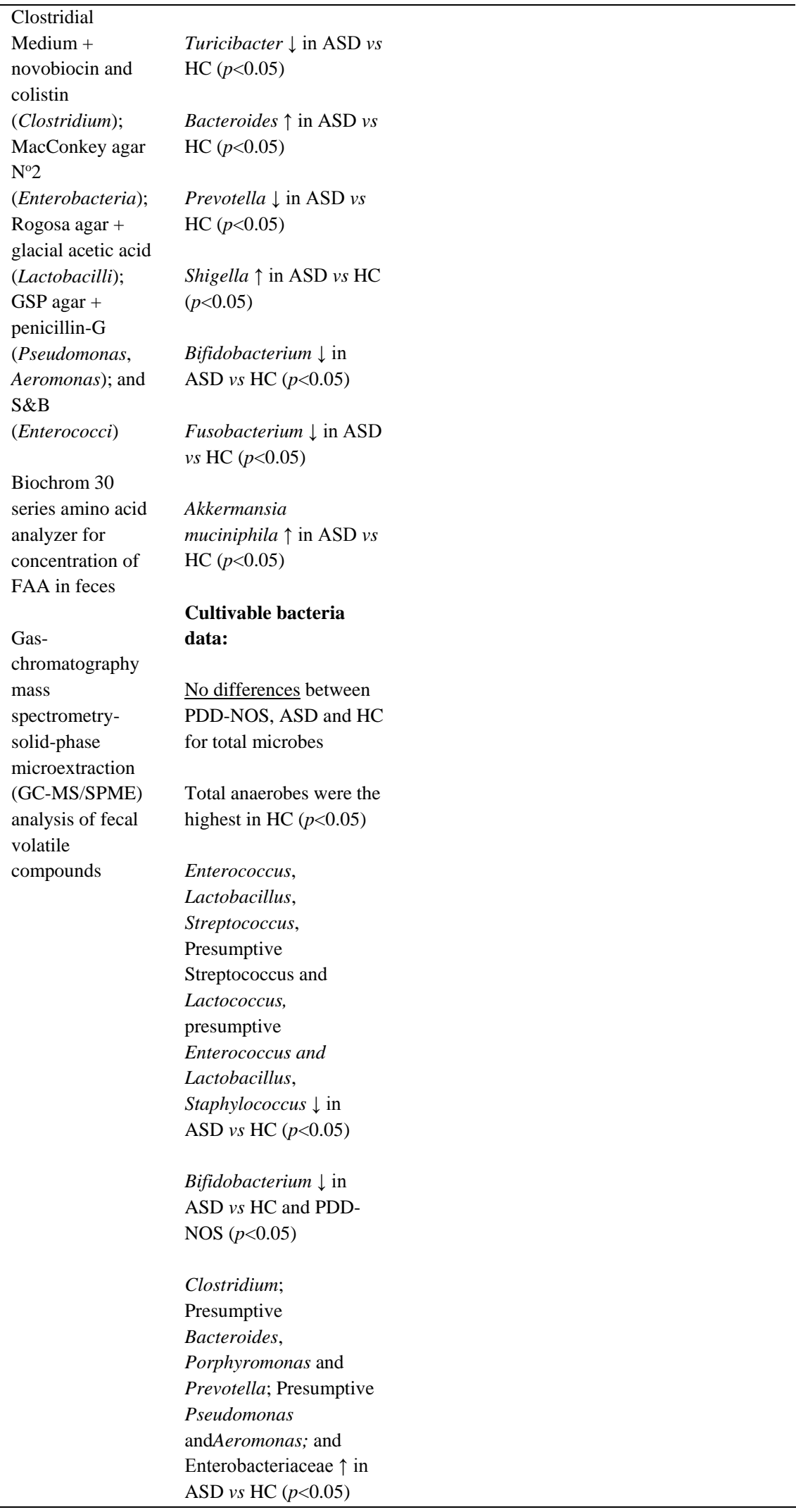




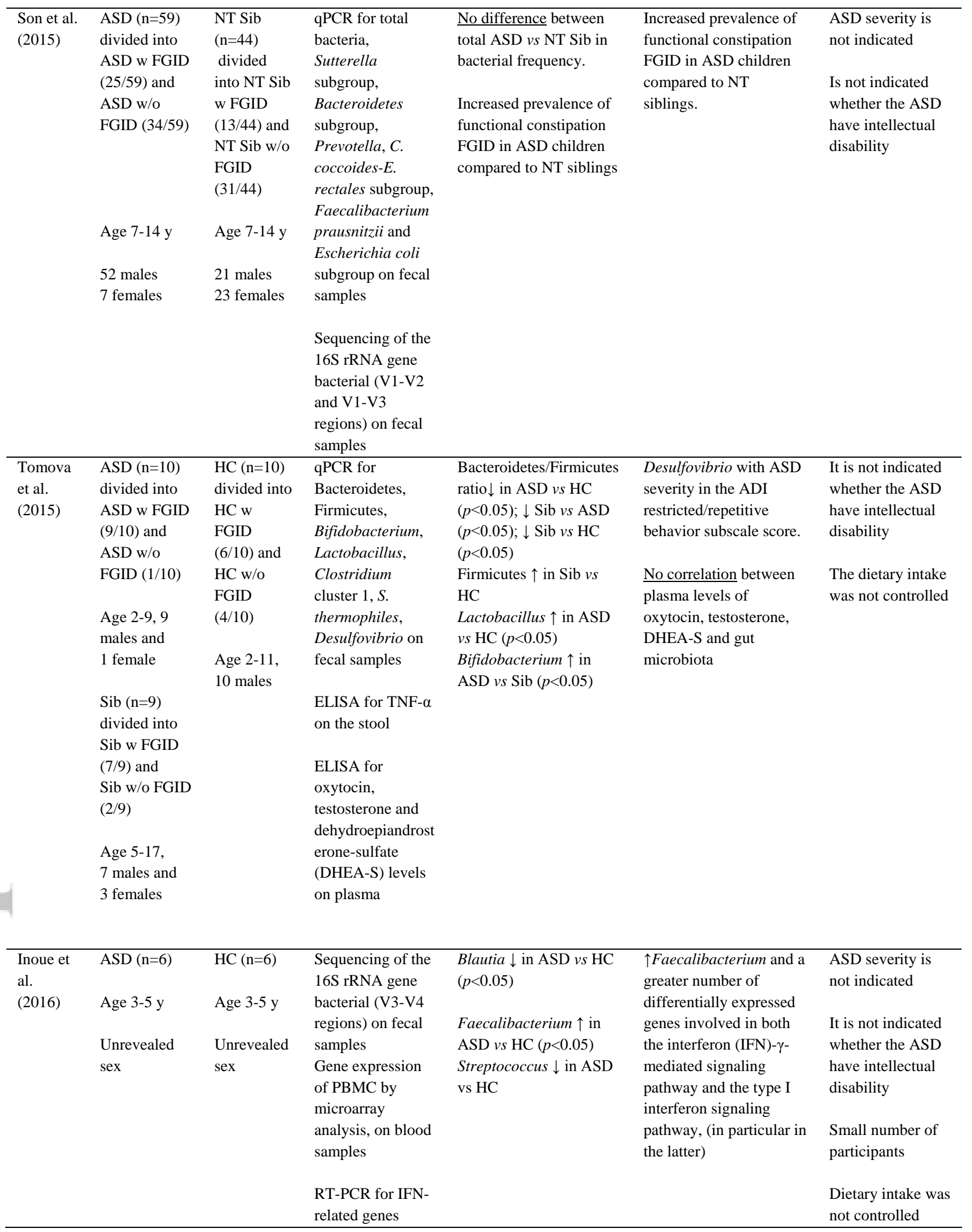




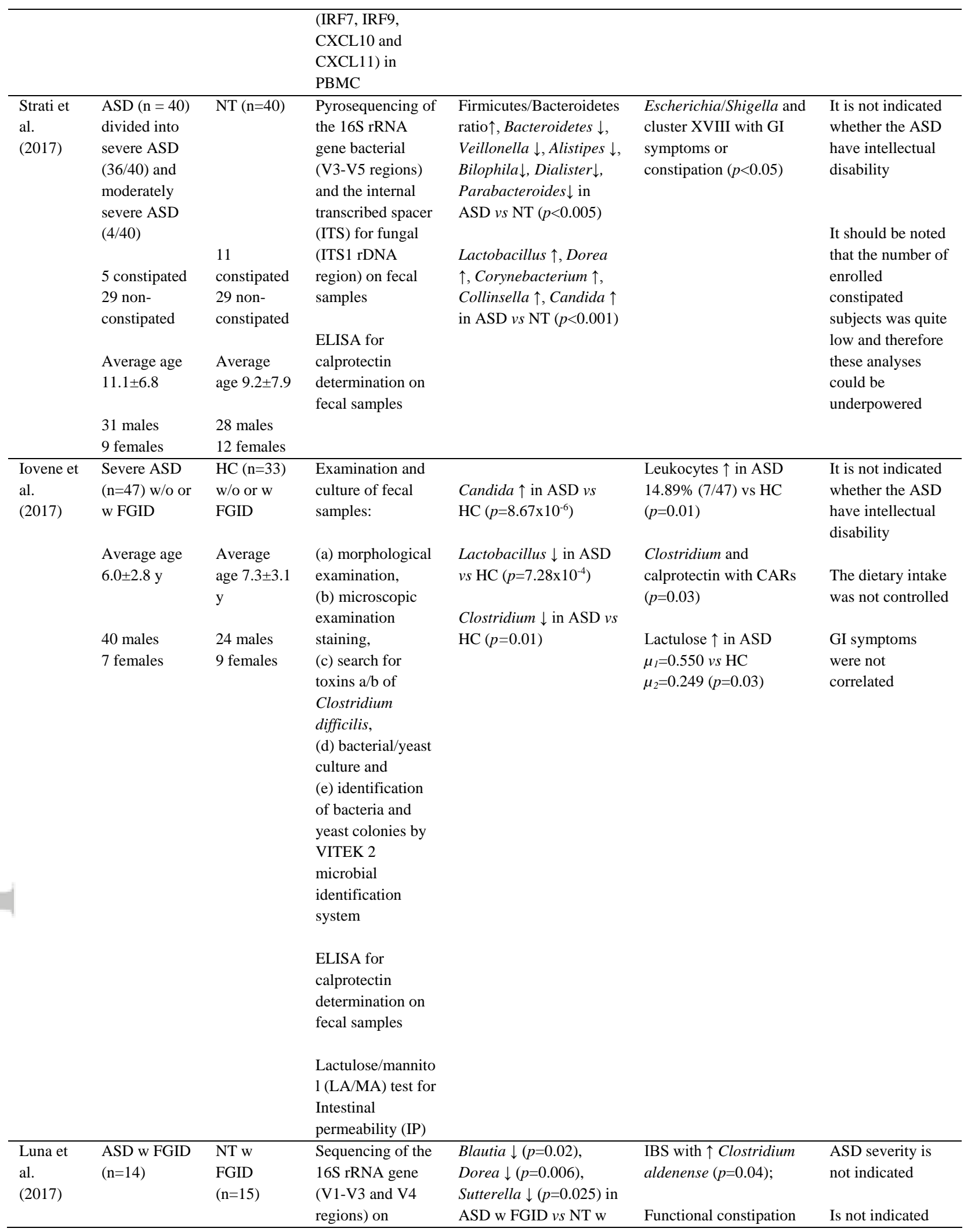




\begin{tabular}{|c|c|c|c|c|c|c|}
\hline & $\begin{array}{l}\text { Age } 4-13 \mathbf{y} \\
14 \text { males }\end{array}$ & $\begin{array}{l}\text { Age 3-18 y } \\
12 \text { males } \\
3 \text { females } \\
\text { NT w/o } \\
\text { FGID (n=6) } \\
\text { Age 3-18 y } \\
6 \text { males }\end{array}$ & $\begin{array}{l}\text { rectum mucosal } \\
\text { biopsy samples } \\
38 \text { cytokines by } \\
\text { the MagPix } \\
\text { system on biopsy } \\
\text { rectum and blood } \\
\text { Serotonin, 5- } \\
\text { HIAA and } \\
\text { Tryptophan by } \\
\text { high-performance } \\
\text { liquid } \\
\text { chromatography } \\
\text { on biopsy rectum }\end{array}$ & $\begin{array}{l}\text { FGID } \\
\text { Clostridium } \\
\text { lituseburense } \uparrow \\
\text { ( } p=0.002) \text {, } \\
\text { Lachnoclostridium } \\
\text { bolteae } \uparrow(p=0.017) \text {, } \\
\text { Lachnoclostridium } \\
\text { hathewayi } \uparrow \text { ( } p=0.03 \text { ), } \\
\text { Clostridium aldenense } \uparrow \\
\text { ( } p=0.03) \text {, and } \\
\text { Flavonifractor plautii } \uparrow \\
\text { ( } p=0.03) \text { in ASD w } \\
\text { FGID vs NT w FGID } \\
\text { and NT w/o FGID } \\
\\
\text { Faecalibacterium } \\
\text { prausnitzii } \uparrow, \text { Roseburia } \\
\text { intestinalis } \uparrow, \\
\text { Oscillospira } \\
\text { valericigenes } \uparrow, \text { and } \\
\text { Bilophila wadsworthia } \uparrow \\
\text { ( } p<0.05 \text { ) in NT w FGID } \\
\text { vs NT w/o FGID }\end{array}$ & 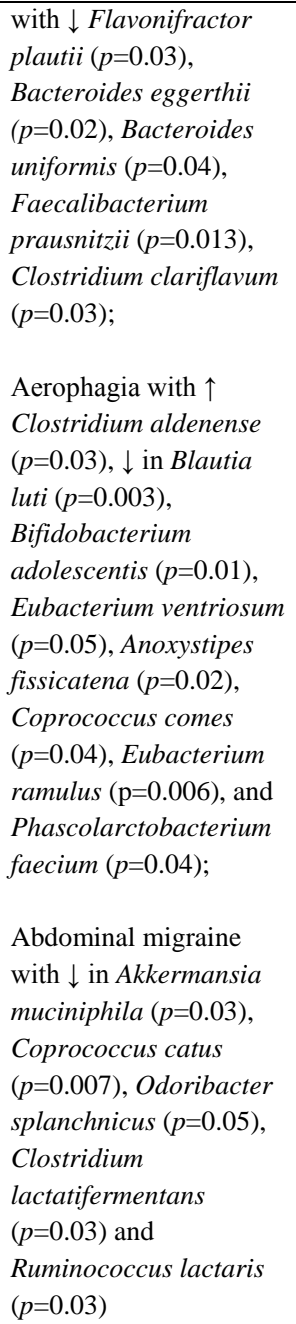 & $\begin{array}{l}\text { whether the ASD } \\
\text { have intellectual } \\
\text { disability } \\
\text { The dietary intake } \\
\text { was not controlled }\end{array}$ \\
\hline & & & & & $\begin{array}{l}\text { Serotonin with } \\
\text { Lachnoclostridium } \\
\text { bolteae ( } p=0.002) \text {, } \\
\text { Lachnoclostridium } \\
\text { hathewayi }(p=0.003) \text { and } \\
\text { Flavonifractor plautii } \\
(p=0.001)\end{array}$ & \\
\hline $\begin{array}{l}\text { Finegold } \\
\text { et al. } \\
\text { (2017) }\end{array}$ & $\begin{array}{l}\begin{array}{l}\text { ASD w FGID } \\
(\mathrm{n}=33)\end{array} \\
\text { Age 2-9 y } \\
\text { Unidentified } \\
\text { sex }\end{array}$ & $\begin{array}{l}\text { HC w/o } \\
\text { FGID } \\
(\mathrm{n}=13) \\
\text { Age 2-9y } \\
\text { Unidentifie } \\
\text { d sex }\end{array}$ & $\begin{array}{l}\text { Selective culture } \\
\text { methods for } \\
\text { Clostridium and } \\
\text { for Clostridium } \\
\text { perfringens strains } \\
\text { on fecal samples: } \\
\text { Brucella and CDC } \\
\text { agar } \\
\text { PCR for } \\
\text { Clostridium } \\
\text { perfringens toxin } \\
\text { genes: alpha } \\
\text { (cpa), beta (cpb), }\end{array}$ & $\begin{array}{l}\text { Clostridium perfringens } \\
\uparrow \text { in ASD w FGID vs HC } \\
(p=0.03)\end{array}$ & $\begin{array}{l}\uparrow \text { counts of Beta 2-Toxin } \\
\text { gene-positive } \\
\text { Clostridium perfringens } \\
\text { in ASD vs HC ( } \mathrm{p}=0.01) \\
\\
\uparrow \text { incidence of Beta 2- } \\
\text { Toxin Clostridium } \\
\text { perfringens in ASD vs } \\
\text { HC }(p=0.01)\end{array}$ & $\begin{array}{l}\text { ASD severity is } \\
\text { not indicated } \\
\text { It is not indicated } \\
\text { whether the ASD } \\
\text { have intellectual } \\
\text { disability } \\
\text { The dietary intake } \\
\text { was not controlled }\end{array}$ \\
\hline
\end{tabular}


beta 2 (cpb2),

epsilon (ctx), iota

(iA) and

enterotoxin (сре)

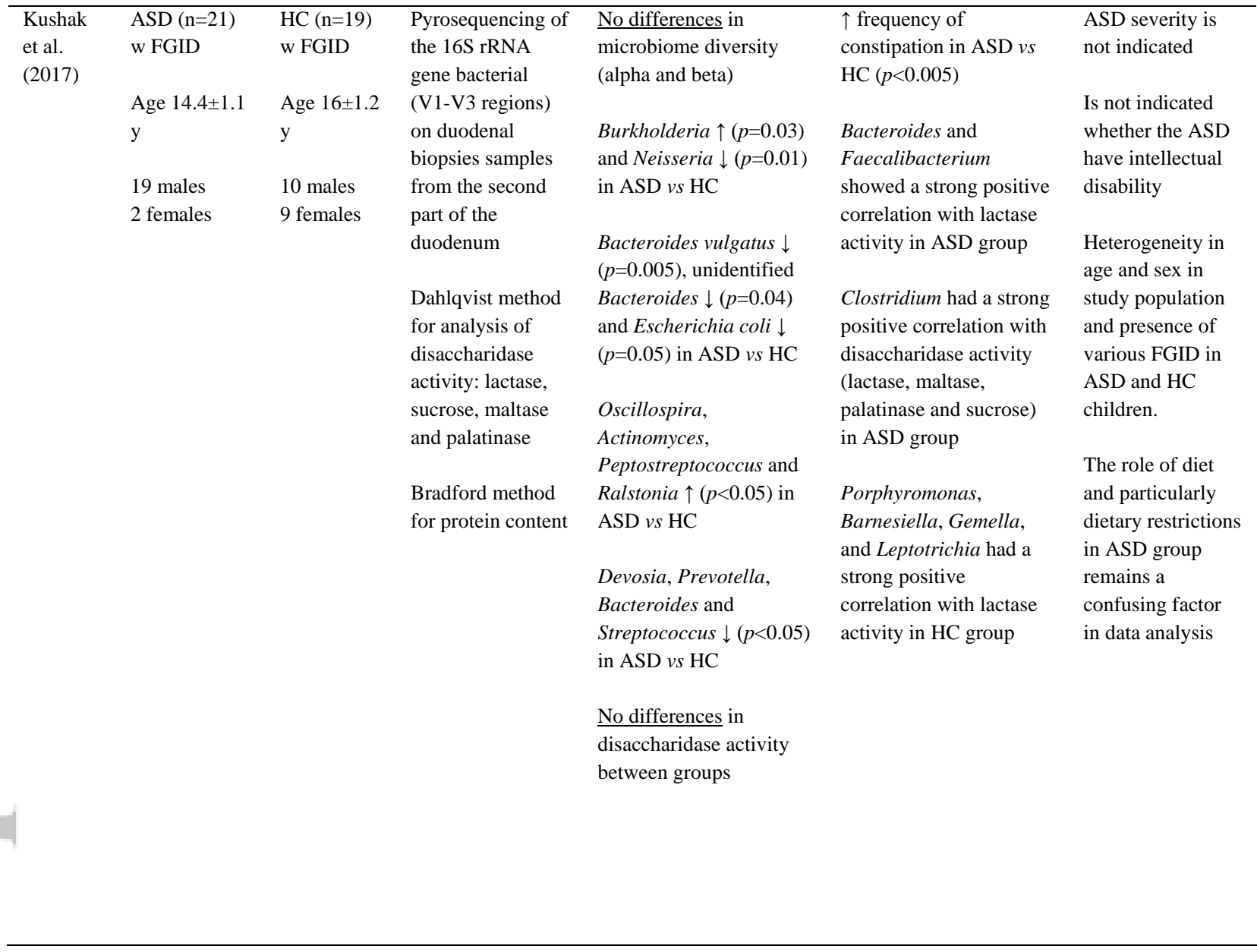




\begin{tabular}{|c|c|c|c|c|c|c|}
\hline $\begin{array}{l}\text { Shaaban } \\
\text { et al. } \\
\text { (2017) }\end{array}$ & $\begin{array}{l}\text { ASD }(\mathrm{n}=30) \\
\text { ASD ( } \mathrm{n}=30) \\
\text { supplemented } \\
\text { with } \\
\text { Lactobacillus } \\
\text { acidophilus, } \\
\text { Lactobacillus } \\
\text { rhamnosus } \\
\text { and } \\
\text { Bifidobacteri } \\
\text { a longum, } \\
\text { during } 3 \\
\text { months. } \\
\text { Age 5-9 y } \\
19 \text { males } \\
11 \text { females }\end{array}$ & $\begin{array}{l}\begin{array}{l}\text { HC parients } \\
(\mathrm{n}=30)\end{array} \\
\text { Age 5-9 y } \\
\text { Unrevealed } \\
\text { sex }\end{array}$ & $\begin{array}{l}\text { Quantitative real- } \\
\text { time PCR in stool } \\
\text { samples }\end{array}$ & $\begin{array}{l}\text { Bifidobacterium } \downarrow \text { in } \\
\text { ASD vs HC ( } p=0.0001 \text { ) } \\
\text { After probiotic } \\
\text { supplementation: } \\
\text { Bifidobacterium } \uparrow \text { and } \\
\text { Lactobacillus } \uparrow \text { in } \\
\text { supplemented-ASD vs } \\
\text { ASD ( } p<0.0001) \\
\text { Body weight } \downarrow \text { in } \\
\text { supplemented-ASD vs } \\
\text { ASD ( } p=0.014) \\
\text { Severity of ASD } \\
\text { symptoms } \downarrow(p=0.0001 \text { ) } \\
\text { and FGID } \downarrow(p<0.05) \text { in } \\
\text { supplemented-ASD vs } \\
\text { ASD }\end{array}$ & $\begin{array}{l}\text { Bifidobacterium } \\
\text { negatively correlated } \\
\text { with the reduction } \\
\text { constipation after } \\
\text { probiotics use } \\
\text { ( } r=-0.441, p<0.015 \text { ) } \\
\text { Improvements in FGID } \\
\text { correlated positively } \\
\text { strongly with } \\
\text { improvements in the } \\
\text { severity of ASD } \\
\text { symptoms after probiotic } \\
\text { use (r=0.674, } p=0.0001 \text { ) } \\
\uparrow \text { Bifidobacterium } \\
\text { correlated negatively } \\
\text { with decreased of body } \\
\text { weight ( } p=0.044 \text { ) and } \\
\text { body weight } \mathrm{z} \text {-score } \\
\text { ( } p=0.033 \text { ) after probiotic } \\
\text { use } \\
\uparrow \text { Lactobacilli correlated } \\
\text { positively with the } \\
\text { decrease in body weight } \\
\text { ( } p=0.006 \text { ) and the } \\
\text { decreased of BMI } \\
\text { ( } p=0.003 \text { ) after probiotic } \\
\text { use }\end{array}$ & $\begin{array}{l}\text { It is not indicated } \\
\text { whether the ASD } \\
\text { have intellectual } \\
\text { disability } \\
\text { A small sample } \\
\text { size, unblinding } \\
\text { and the lack of a } \\
\text { placebo control } \\
\text { group } \\
\text { The cohort } \\
\text { received } \\
\text { behavioral therapy } \\
\text { during the } \\
\text { probiotic's } \\
\text { administration. }\end{array}$ \\
\hline $\begin{array}{l}\text { Gora et } \\
\text { al. } \\
\text { (2018) }\end{array}$ & $\begin{array}{l}\text { ASD }(\mathrm{n}=29) \\
\text { w FGID } \\
\text { (49 isolated } \\
\text { strains of } \\
\text { Clostridium } \\
\text { perfringens) } \\
\text { Age 3.5-18 y } \\
23 \text { males } \\
9 \text { females }\end{array}$ & $\begin{array}{l}\text { HC }(\mathrm{n}=17) \\
\text { (30 isolated } \\
\text { strains of } \\
\text { Clostridium } \\
\text { perfringens } \\
\text { ) } \\
\text { Obese } \\
\text { children } \\
\text { (n=24) (32 } \\
\text { isolated } \\
\text { strains of } \\
\text { Clostridium } \\
\text { perfringens } \\
\text { ) }\end{array}$ & $\begin{array}{l}\text { Selective culture } \\
\text { method for fecal } \\
\text { samples: } \\
\text { Columbia blood } \\
\text { and Reinforced } \\
\text { Clostridial agar } \\
\text { under anaerobic } \\
\text { conditions. } \\
\text { Hemolysis test, } \\
\text { lecithinase and } \\
\text { lipase production } \\
\text { on Egg-Yolk- } \\
\text { Agar, and } \\
\text { identified with use } \\
\text { of ANC cards in } \\
\text { VITEK } 2 \\
\text { compact. } \\
\text { Subcultured in } \\
\text { BHI broth and } \\
\text { GeneMATRIX } \\
\text { DNA Purifi- } \\
\text { cation Kit by } \\
\text { DNA Gdansk for } \\
\text { isolation of DN }\end{array}$ & $\begin{array}{l}\text { The cpa gene encoding } \\
\text { alpha toxin was present } \\
\text { in all } 111 \text { (100\%) strains } \\
\text { The } c p b 2 \text { gene encoding } \\
\text { beta2 toxin was found in: } \\
45 / 49 \text { (91.8\%) strains } \\
\text { isolated from ASD } \\
\text { children, } 17 / 30 \text { (56.7\%) } \\
\text { strains isolated from } \\
\text { healthy subjects } \\
\text { ( } p<0.001) \text {, and } 12 / 32 \\
\text { (37.5\%) strains isolated } \\
\text { from obese children } \\
\text { ( } p<0.001) \\
\text { Clostridium perfringens } \\
\text { strains with the ability to } \\
\text { produce beta2 toxin } \\
\text { (cpb2 gene) were } \\
\text { detected in: } \\
27 / 29 \text { (93.1\%) ASD, } \\
10 / 17 \text { (58.8\%) HC } \\
\text { ( } p<0.008) \text { and } 11 / 24 \\
(45.8 \%) \text { obese children } \\
\text { ( } p<0.001) \\
\text { No differences between } \\
\text { HC and obese children } \\
\text { ( } c p b 2 \text { and } C l o s t r i d i u m \\
\text { perfringens with } c p b 2)\end{array}$ & & $\begin{array}{l}\text { ASD severity is } \\
\text { not indicated. } \\
\text { Is not indicated } \\
\text { whether the ASD } \\
\text { have intellectual } \\
\text { disability } \\
\text { A small number } \\
\text { of studied patients } \\
\text { and strains }\end{array}$ \\
\hline
\end{tabular}




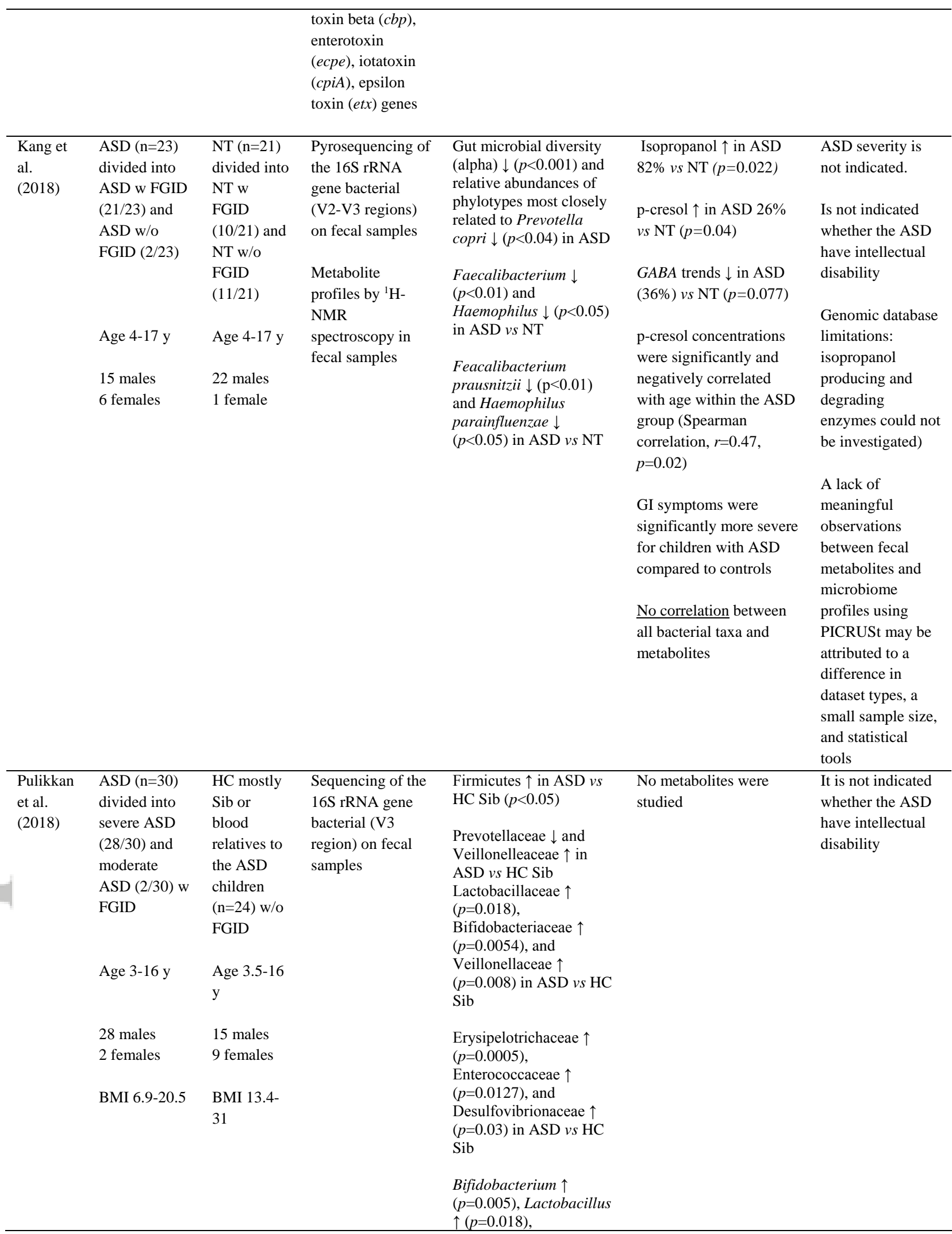




\begin{tabular}{|c|c|c|c|c|c|c|}
\hline & & & & $\begin{array}{l}\text { Megasphaera } \uparrow \\
(p=0.0008) \text { and } \\
\text { Mirsuokella } \uparrow(p=0.007) \\
\text { in ASD vs HC Sib } \\
99 \% \text { of Lactobacillus } \\
\text { was Lactobacillus } \\
\text { ruminis in ASD group }\end{array}$ & & \\
\hline $\begin{array}{l}\text { Rose et } \\
\text { al. } \\
\text { (2018) }\end{array}$ & $\begin{array}{l}\text { ASD w FGID } \\
\text { (blood: } \mathrm{n}=20 \text {, } \\
15 \text { males, } 5 \\
\text { females) } \\
\text { (stool: } \mathrm{n}=21 \text {, } \\
17 \text { males, } 4 \\
\text { females) } \\
\text { ASD w/o } \\
\text { FGID (blood: } \\
\mathrm{n}=26,19 \\
\text { males, } 7 \\
\text { females) } \\
\text { (stool: } \mathrm{n}=29 \text {, } \\
25 \text { males, } 4 \\
\text { females) } \\
\text { Age 3-12 y }\end{array}$ & $\begin{array}{l}\text { HC w } \\
\text { FGID } \\
\text { (blood: } \\
\text { n=6, } 5 \\
\text { males, } 1 \\
\text { female) } \\
\text { (stool: n=7, } \\
6 \text { males, } 1 \\
\text { female) } \\
\text { HC w/o } \\
\text { FGID } \\
\text { (blood: } \\
\text { n=35, } 24 \\
\text { males, } 11 \\
\text { females) } \\
\text { (stool: } \\
\text { n=34, } 32 \\
\text { males, } 2 \\
\text { females) } \\
\text { Age 3-12 y }\end{array}$ & $\begin{array}{l}\text { Sequencing of the } \\
\text { 16S rRNA gene } \\
\text { bacterial (V3-V4 } \\
\text { regions) on fecal } \\
\text { samples } \\
\text { Multiplexing bead } \\
\text { immunoassay for } \\
\text { L-1alpha, IL- } \\
\text { 1beta, IL-6, IL-12 } \\
\text { (p40 \& p70), } \\
\text { TNFalpha, IFNc } \\
\text { (TH1), IL-4, IL- } \\
\text { 13 (TH2), IL-10, } \\
\text { TGFbeta1, IL-5, } \\
\text { IL-15 and IL-17 } \\
\text { cytokines in } \\
\text { PBMC from blood } \\
\text { samples }\end{array}$ & $\begin{array}{l}\text { Bacteroidaceae } \uparrow \text {, } \\
\text { Lachnospiraceae } \uparrow \text {, } \\
\text { Ruminococcaceae } \uparrow \text { and } \\
\text { Prevotellaceae } \uparrow \text { in ASD } \\
\text { w GI vs HC w GI } \\
\text { Il-5, IL-15 and IL-17 } \uparrow \\
\text { in ASD w FGID vs ASD } \\
\text { w/o FGID (after } \\
\text { exposure to the TLR-4 } \\
\text { agonist LPS) } \\
\text { TGFbeta1 } \downarrow \text { in ASD w } \\
\text { FGID vs ASD w/o FGID } \\
\text { and HC w/o FGID } \\
(p<0.05 \text { ) (under the } \\
\text { majority of conditions } \\
\text { examined) }\end{array}$ & $\begin{array}{l}\text { No correlation between } \\
\text { cytokines levels or Hp } \\
\text { and fecal microbiota } \\
\text { Differences in the } \\
\text { microbiome composition } \\
\text { of children with ASD vs } \\
\text { HC groups, irrespective } \\
\text { of FGID }\end{array}$ & $\begin{array}{l}\text { ASD severity is } \\
\text { not indicated. } \\
\text { It is not indicated } \\
\text { whether the ASD } \\
\text { have intellectual } \\
\text { disability } \\
\text { Limited sample } \\
\text { size and younger } \\
\text { age of the HC } \\
\text { with FGID group }\end{array}$ \\
\hline $\begin{array}{l}\text { Coretti et } \\
\text { al. } \\
(2018)\end{array}$ & $\begin{array}{l}\text { ASD }(n=11, \\
9 \text { males, } 2 \\
\text { females) } \\
\text { Age } 2-4 \text { y }\end{array}$ & $\begin{array}{l}\text { HC }(\mathrm{n}=14, \\
8 \text { males, } 6 \\
\text { females) } \\
\text { Age } 2-4 \text { y }\end{array}$ & $\begin{array}{l}\text { Sequencing of the } \\
\text { 16S rRNA gene } \\
\text { bacterial (V3-V4 } \\
\text { regions) on fecal } \\
\text { samples } \\
\text { Droplet Digital } \\
\text { PCR (ddPCR) }\end{array}$ & $\begin{array}{l}\text { Bacteroidetes/Firmicutes } \\
\text { ratio } \uparrow(p<0.05) \text { in ASD } \\
\text { vs HC } \\
\text { Actinobacteria } \downarrow \\
(p=0.004), \text { Bacteroidetes } \\
\uparrow(p=0.04), \\
\text { Proteobacteria } \uparrow \\
(p=0.004) \text { in ASD vs HC }\end{array}$ & $\begin{array}{l}\text { Faecalibacterium } \\
\text { prausnitzii, B. uniformis, } \\
\text { were positively } \\
\text { correlated to the ADOS } \\
\text { score ( } r=0.767 \text { and } r= \\
0.84, p<0.001 \text { ) ASD vs } \\
\text { HC } \\
\text { Faecalibacterium } \\
\text { prausnitzii, } \\
\text { Ruminococcus torques } \\
\text { and Eubacterium } \\
\text { eligens, were positively } \\
\text { associated to butyrate } \\
\text { level } \\
\text { Butyrate } \uparrow(p=0.005 \text { ) } \\
\text { ASD vs HC } \\
\text { Phosphate } \\
\text { butyryltransferase gene } \\
\uparrow, \text { acetate CoA- } \\
\text { transferase alpha subunit } \\
\text { gene } \uparrow ~(p<0.05 \text { ) ASD vs } \\
\text { HC } \\
\text { Ruminococcus torques } \uparrow,\end{array}$ & $\begin{array}{l}\text { ASD severity is } \\
\text { not indicated. } \\
\text { It is not indicated } \\
\text { whether the ASD } \\
\text { have intellectual } \\
\text { disability } \\
\text { A small number } \\
\text { of studied patients } \\
\text { and strains }\end{array}$ \\
\hline
\end{tabular}




\begin{tabular}{|c|c|c|c|c|c|c|}
\hline & & & & $\begin{array}{l}\text { Faecalibacterium } \\
\text { prausnitzii } \uparrow,(p<0.05) \\
\text { in ASD vs HC }\end{array}$ & $\begin{array}{l}\text { Beta-hexosaminidase } \\
\text { (K12373) (>0.01\%) } \uparrow \\
\text { ASD vs HC }\end{array}$ & \\
\hline $\begin{array}{l}\text { Zhang et } \\
\text { al. } \\
\text { (2018) }\end{array}$ & $\begin{array}{l}\text { ASD w FGID } \\
(\mathrm{n}=35,29 \\
\text { males, } 6 \\
\text { females) } \\
\text { Age 3-8 y }\end{array}$ & $\begin{array}{l}\text { HC }(n=6,5 \\
\text { males, } 1 \\
\text { females) } \\
\text { Age 3-8 y }\end{array}$ & $\begin{array}{l}\text { Sequencing of the } \\
\text { 16S rRNA gene } \\
\text { bacterial (V3-V4 } \\
\text { regions) on fecal } \\
\text { samples. }\end{array}$ & $\begin{array}{l}\text { Bacteroidetes } \uparrow \text { in ASD } \\
\text { w FGID vs HC }(p<0.05) \\
\text { Firmicutes } \downarrow \text { in ASD w } \\
\text { FGID vs HC }(p<0.05) \\
\text { Veillonella, } \\
\text { Streptococcus, } \\
\text { Escherichia, } \\
\text { Actinomyces, } \\
\text { Parvimonas, Bulleida } \\
\text { and Peptoniphilus } \downarrow \text { in } \\
\text { ASD w FGID vs HC } \\
(p<0.05)\end{array}$ & $\begin{array}{l}\text { Positive microbe-based } \\
\text { link between } \\
\text { periodontitis and ASD } \\
\text { Negative microbe-based } \\
\text { link between type } 1 \\
\text { diabetes, constipation, } \\
\text { IBS, psoriasis and ASD }\end{array}$ & $\begin{array}{l}\text { ASD severity is } \\
\text { not indicated. } \\
\text { It is not indicated } \\
\text { whether the ASD } \\
\text { have intellectual } \\
\text { disability } \\
\text { A small number } \\
\text { of studied patients } \\
\text { and strains }\end{array}$ \\
\hline $\begin{array}{l}\text { Berding } \\
\text { and } \\
\text { Donovan } \\
\text { (2018) }\end{array}$ & $\begin{array}{l}\text { ASD }(n=26, \\
19 \text { males, } 7 \\
\text { females) } \\
\text { Age 2-7 y }\end{array}$ & $\begin{array}{l}\text { HC }(\mathrm{n}=32, \\
19 \text { males, } \\
13 \text { females }) \\
\text { Age } 2-7 \text { y }\end{array}$ & $\begin{array}{l}\text { Real time qPCR } \\
\text { for total bacteria, } \\
\text { Lactobacillus, } \\
\text { Bifidobacterium, } \\
\text { Prevotella, } \\
\text { Clostridium } \\
\text { perfringens, and } \\
\text { C. difficile } \\
\text { Gas- } \\
\text { chromatography } \\
\text { mass spectrometry } \\
\text { of VFA on fecal } \\
\text { samples }\end{array}$ & $\begin{array}{l}\text { Firmicutes } \uparrow \text { in ASD vs } \\
\text { HC }(p<0.03) \\
\text { Coriobacteriaceae } \uparrow \\
(p=0.04) \text {, } \\
\text { Peptostreptococcaceae } \uparrow \\
(p=0.05 \text { ) and } \\
\text { Rikenellaceae } \downarrow \\
\text { ( } p=0.005) \text { in ASD vs HC } \\
\text { Clostridium, Blautia, and } \\
\text { Roseburia } \uparrow \text { in ASD vs } \\
\text { HC ( } p \leq 0.05) \\
\text { Butyricimonas, } \\
\text { Butyrivibrio, } \\
\text { Faecalibacterium, } \\
\text { Dialister, and } \\
\text { Bilophila } \downarrow \text { in ASD vs } \\
\text { HC ( } p \leq 0.05 \text { ) } \\
\text { Bifidobacterium } \downarrow \text { in } \\
\text { ASD vs HC ( } p=0.04 \text { ) } \\
\text { C. perfringens } \downarrow \text { in ASD } \\
\text { vs HC ( } p=0.009)\end{array}$ & $\begin{array}{l}\text { Intake of } \\
\text { insoluble dietary fiber } \\
\text { was negatively } \\
\text { correlated ( } r=-0.4 \text {; } \\
p=0.04 \text { ) with abundance } \\
\text { of Clostridiales. } \\
\text { Faecalibacterium } \\
\text { abundance was } \\
\text { positively correlated } \\
\text { with servings per day of } \\
\text { fried food ( } r=0.43 \text {; } \\
p=0.0 \text { ), but negatively } \\
\text { correlated with servings } \\
\text { per day of fruit ( } r=-0.39 \text {; } \\
p=0.05 \text { ) }\end{array}$ & $\begin{array}{l}\text { ASD severity is } \\
\text { not indicated. } \\
\text { It is not indicated } \\
\text { whether the ASD } \\
\text { have intellectual } \\
\text { disability }\end{array}$ \\
\hline
\end{tabular}

Note: $\mathrm{w}$ = with; w/o = without; ASD = Autism Spectrum Disorder; HC = Healthy control;

FGID = Functional Gastro-Intestinal Disorders; NT = Neurotypical; NT Sib = Neurotypical

siblings; Sib = siblings; $\mathrm{y}=$ years $;$ ADI = Autism Diagnostic Interview DHEA-S =

dehydroepiandrosteronesulfate; PDD-NOS = Pervasive Developmental Disorder Not 
Otherwise Specified; IBS = Irritable Bowel Syndrome; BMI = Body Mass Index, FAA = Free Amino Acids, NT=HC, VFA: volatile fatty acids 